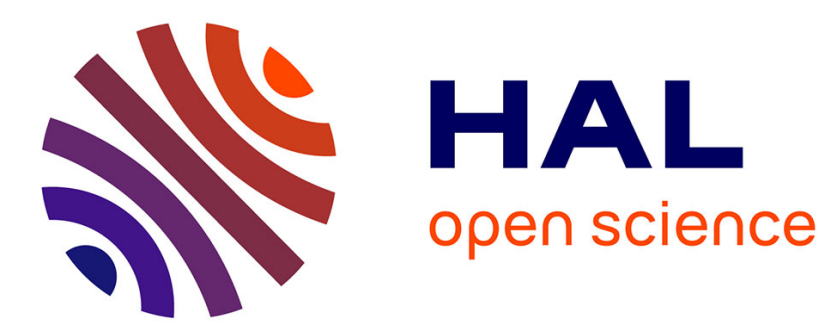

\title{
Impacts of Indian and Atlantic oceans on ENSO in a comprehensive modeling framework
}

Pascal Terray, Sébastien Masson, Chloé Prodhomme, Mathew Koll Roxy, K. P. Sooraj

\section{- To cite this version:}

Pascal Terray, Sébastien Masson, Chloé Prodhomme, Mathew Koll Roxy, K. P. Sooraj. Impacts of Indian and Atlantic oceans on ENSO in a comprehensive modeling framework. Climate Dynamics, 2016, 46 (7), pp.2507-2533. 10.1007/s00382-015-2715-x . hal-01191049

\section{HAL Id: hal-01191049 \\ https://hal.sorbonne-universite.fr/hal-01191049}

Submitted on 1 Sep 2015

HAL is a multi-disciplinary open access archive for the deposit and dissemination of scientific research documents, whether they are published or not. The documents may come from teaching and research institutions in France or abroad, or from public or private research centers.
L'archive ouverte pluridisciplinaire HAL, est destinée au dépôt et à la diffusion de documents scientifiques de niveau recherche, publiés ou non, émanant des établissements d'enseignement et de recherche français ou étrangers, des laboratoires publics ou privés. 
$5 \quad$ Pascal Terray ${ }^{1,2}$, Sébastien Masson ${ }^{1}$, Chloé Prodhomme ${ }^{4}$, Mathew Koll Roxy ${ }^{3}$, K P Sooraj $^{3}$

6

$7{ }^{1}$ Sorbonne Universités (UPMC, Univ Paris 06)-CNRS-IRD-MNHN, LOCEAN Laboratory, 4 8 place Jussieu, F-75005 Paris, France

${ }^{2}$ Indo-French Cell for Water Sciences, IISc-IITM-NIO-IRD Joint International Laboratory, IITM, Pune, India

$9{ }^{3}$ Centre for Climate Change Research, Indian Institute of Tropical Meteorology, Pune, India

$10{ }^{4}$ Climate Forecasting Unit, Institut Català de Ciències del Clima (IC3), Barcelona, Spain

11

Revised for Climate Dynamics

13

11 June 2015

14 
The impact of the Indian and Atlantic oceans variability on El Niño-Southern-Oscillation (ENSO) phenomenon is investigated through sensitivity experiments with the SINTEX-F2 coupled model. For each experiment, we suppressed the Sea Surface Temperature (SST) variability in either the Indian or Atlantic oceans by applying a strong nudging of the SST toward a SST climatology computed either from a control experiment or observations.

In the sensitivity experiments where the nudging is done toward a control SST climatology, the Pacific mean state and seasonal cycle are not changed. Conversely, nudging toward an observed SST climatology in the Indian or Atlantic domain significantly improves the mean state and seasonal cycle, not only in the nudged domain, but also in the whole tropics.

These experiments also demonstrate that decoupling the Indian or Atlantic variability modifies the phase-locking of ENSO to the annual cycle, influences significantly the timing and processes of ENSO onset and termination stages, and, finally, shifts to lower frequencies the main ENSO periodicities. Overall, these results suggest that both the Indian and Atlantic SSTs have a significant damping effect on ENSO variability and promote a shorter ENSO cycle. The reduction of ENSO amplitude is particularly significant when the Indian Ocean is decoupled, but the shift of ENSO to lower frequencies is more pronounced in the Atlantic decoupled experiments. These changes of ENSO statistical properties are related to stronger Bjerknes and thermocline feedbacks in the nudged experiments.

During the mature phase of El Niño events, warm SST anomalies are found over the Indian and Atlantic oceans in observations or the control run. Consistent with previous studies, the nudged experiments demonstrate that these warm SSTs induce easterly surface wind anomalies over the far western equatorial Pacific, which fasten the transition from El Niño to La Niña and promote a shorter ENSO cycle in the control run. These results may be explained by modulations of the Walker circulation induced directly or indirectly by the Indian and Atlantic SSTs. Another interesting result is that decoupling the Atlantic or Indian oceans change the timing of ENSO onset and the relative role of other ENSO atmospheric precursors such as the extra-tropical Pacific Meridional Modes or the Western North Pacific SSTs.

Keywords: El Niño-Southern Oscillation; Indian Ocean; Atlantic Ocean; ocean-atmosphere interactions; coupled climate model. 


\section{Introduction}

El Niño-Southern Oscillation (ENSO) is the dominant mode of climate variability in the Tropics (Clarke 2008). ENSO has a far-reaching effect leading to extensive floods or anomalous droughts in many regions of the globe. Thus, advanced and accurate forecast of ENSO has significant applications, but is still a challenging problem as illustrated by the complete failure of the recent forecasts issued in boreal spring of 2014 by the different operational predictions groups, which indicated a high chance of a major El Niño evolving over the summer, autumn and winter of 2014 (Tollefson 2014). Basic properties of ENSO are now rather well understood and simulated by current Coupled General Circulation Models (CGCMs). However, anticipating its behavior before boreal spring and understanding its relationship with other tropical and extra-tropical regions are still related and challenging problems.

While the classical picture is that the Indian and Atlantic oceans only play a passive role in ENSO evolution, many new studies suggest an active role of these two basins on ENSO. First, there is a lot of studies focusing on the role of Indian Ocean Basin-wide (IOB) warming or Indian Ocean Dipole (IOD) in ENSO onset and evolution (Kug and Kang 2006; Kug et al. 2006a, 2006b; Ohba and Ueda 2007; Izumo et al. 2010; Luo et al. 2010; Dayan et al. 2014). They pointed out that there are significant differences in ENSO evolution with and without IOB warming or IOD in observations. It has been suggested that the ENSO-forced IOB warming might affect atmospheric circulation over the western Pacific to fasten the turnabout of the ENSO cycle (Kug and Kang 2006). Izumo et al. (2010) claimed that skillful ENSO forecasts are possible 14 months in advance with the help of the IOD. These results are related to the fact that zonal wind anomalies associated with the IOB or IOD may propagate from the equatorial Indian Ocean into the equatorial Pacific before the onset of El Niño or during the transitions from El Niño to La Niña and are thus useful parameters to overcome the spring predictability barrier of ENSO (Barnett 1983; Clarke and Van Gorder 2003; Clarke 2008; Kug et al. 2010). Sea Surface Temperature (SST) anomalies over the South Indian Ocean may also act as a remote forcing to promote wind anomalies in the western equatorial Pacific (Dominiak and Terray 2005; Terray 2011; Boschat et al. 2013). These recent studies imply that the Indian Ocean may be an integral part of the ENSO dynamics. But, the relative roles of the IOD, IOB or South Indian Ocean SSTs in ENSO are difficult to assess from observations because these relationships involve a complex interplay of ocean and 
atmospheric processes in both the Indian and Pacific oceans (Santoso et al. 2012; Dayan et al. 2014).

The relationships between the tropical Atlantic Ocean and ENSO have also been the focus of many recent studies (Dommenget et al. 2006; Rodriguez-Fonseca et al. 2009; Jansen et al. 2009; Ding et al. 2012; Keenlyside et al. 2013; Ham et al. 2013a, b; Polo et al. 2014; Kurchaski et al. 2015). Several of these studies emphasized that the so-called Atlantic El Niño events during boreal summer can modulate ENSO variability through a modulation of the Walker circulation (Frauen and Dommenget 2012; Ding et al. 2012; Polo et al. 2014). Interestingly, some Atlantic Niñas coincide with the strongest El Niño cases (i.e., 1982/1983 and 1997/1998) in the twentieth century. This implies that Atlantic Niñas may help to develop the strongest El Niño events in the Pacific and improve ENSO predictions (Keenlyside et al. 2013). The lead relationship between Atlantic variability and ENSO also exists in boreal winter and early spring, involving the southern Atlantic (Terray 2011; Boschat et al. 2013) or the subtropical North Atlantic (Ham et al. 2013a,b; Dayan et al. 2013). Thus, a large variety of mechanisms may account for the statistical relationships between the Atlantic and Pacific basins in addition to the traditional ENSO teleconnection (Chang et al. 2006).

The complex interactions between ENSO, Indian and Atlantic oceans make it difficult, and probably almost impossible, to determine their cause-and-effect relationships using observational analyses or forced atmospheric experiments (Dayan et al. 2014). All the puzzling results discussed above need to be verified with a comprehensive CGCM in order to demonstrate causal relationships between Atlantic or Indian ocean variability and ENSO. CGCM experiments that can isolate the coupling processes within and external to the Pacific Ocean are thus a useful alternative for testing the various hypotheses.

Basin decoupling or partially coupled experiments have already been performed to study the inter-basin interactions between the Indian, Atlantic and Pacific oceans (e.g., Yu et al. 2002, 2009; Yu 2005; Wu and Kirtman 2004; Kug et al. 2006b; Santoso et al. 2012 for the Indian Ocean; Rodriguez-Fonseca et al. 2009; Ding et al. 2012; Keenlyside et al. 2013; Polo et al. 2014 for the Atlantic Ocean). However, very few studies have performed decoupling or partially coupled experiments for both the Indian and Atlantic oceans in exactly the same modeling framework, except Dommenget et al. (2006) or Frauen and Dommenget (2012). 
115 Frauen and Dommenget (2012) argued that knowing the initial conditions and simulating the

116 evolution in the tropical Atlantic is more important than the knowledge of Indian Ocean

117 evolution for ENSO predictability. On the other hand, Keenlyside et al. (2013), using 118 numerical experiments with observed Atlantic SSTs nudged into a coupled model, found that 119 Atlantic variability during boreal winter and spring is irrelevant for ENSO prediction, only 120 Atlantic Ocean SSTs during boreal summer do matter for ENSO. Similarly, the CGCM 121 results obtained so far on the impact of Indian Ocean SSTs on ENSO are somewhat 122 controversial. Some of these previous CGCM studies find that Indian Ocean coupling could 123 enhance ENSO variability (Yu et al. 2002, 2009; Wu and Kirtman 2004), while others found 124 the reverse (Dommenget et al. 2006; Kug et al. 2006a; Frauen and Dommenget 2012; Santoso 125 et al. 2012) or no impact of the Indian Ocean coupling on ENSO amplitude (Yeh et al. 2007).

126

127

The inconsistencies in these numerical experiments could be partly due to model biases, too short simulations, the use of partly simplified coupled models or flux adjustments, or different decoupling strategies. The most common approach in the different studies is to replace the simulated SSTs in a basin with a monthly SST climatology. However, some studies used a SST climatology estimated from observations (Yu et al. 2002, 2009), while others used a SST climatology from a control simulation in the decoupled experiments (Wu and Kirtman 2004; Kug et al. 2006b; Santoso et al. 2012). These different approaches may induce different conclusions because SST biases may vary from one model to another. Furthermore, by using SST climatology from observations, these SST biases are removed, but we cannot ascertain that the changes of variability in the decoupled experiment are due to the SST biases or to the absence of variability in the basin in which the ocean-atmosphere coupling has been turned off.

Here, we employ a fully coupled climate model without any flux adjustments and a realistic ENSO variability to address these issues. More precisely, we use a series of basin-decoupling CGCM experiments using both observed and simulated SST climatologies to discriminate the relative roles of Indian and Atlantic basins on ENSO variability. While our modeling results are consistent with some previous studies and support the hypothesis that both the Indian and Atlantic SST variability accelerates the decaying phase of El Niño, they also suggest that Indian and Atlantic variability plays an important role in ENSO onset and modulates ENSO feedbacks. 
The article is organized as follows. In section 2, we give a brief overview to the SINTEX-F2 coupled model, the design of the decoupled experiments and the statistical tools used here. Section 3 is devoted to the validation of ENSO variability in SINTEX-F2 and to a description of the changes of ENSO properties and feedbacks directly associated with Indian and Atlantic variability in the decoupled experiments. Sections 4 and 5 focus more specifically on the onset and decaying stages of ENSO, which account for many of the simulated ENSO changes. Conclusions and prospects for future work are given in section 6.

\section{Coupled model, experimental design and statistical tools}

\section{2.a Model setup and sensitivity experiments}

In order to study the impact of the tropical Atlantic and Indian oceans on ENSO, the SINTEX-F2 CGCM is employed (Masson et al. 2012). The atmosphere model is ECHAM5.3 and is run at $\mathrm{T} 106$ spectral resolution (about $1.125^{\circ}$ by $1.125^{\circ}$ ) with 31 hybrid sigma-pressure levels (Roeckner et al. 2003). The oceanic component is NEMO (Madec 2008), using the ORCA05 horizontal resolution $\left(0.5^{\circ}\right), 31$ unevenly spaced vertical levels and including the LIM2 ice model (Timmermann et al. 2005). Atmosphere and ocean are coupled by means of the Ocean-Atmosphere-Sea Ice-Soil (OASIS3) coupler (Valcke 2006). The coupling information, without any flux corrections, is exchanged every $2 \mathrm{~h}$. The model does not require flux adjustment to maintain a stable climate, and simulates a realistic mean state and interannual variability in the tropical Pacific (Masson et al. 2012). It has also been shown to perform very well in ENSO prediction studies (Luo et al. 2005a). The performance of the SINTEX-F2 model in simulating the seasonal cycle in the Indian areas has been assessed in Terray et al. (2012) and Prodhomme et al. (2014) and is not repeated here.

We first run a 210-years control experiment (named REF hereafter) with the standard coupled configuration of SINTEX-F2. The mean SST climatology estimated from the REF simulations has been compared to SST data from 1979-2012 taken from the Hadley Center Sea Ice and Sea Surface Temperature dataset version 1.1 (HadISST1.1; Rayner et al. 2003). The tropical areas are generally too warm and extra-tropics too cold (Figs. 1a,b). Mean deviations from observed SST is less than $1^{\circ} \mathrm{C}$ over much of the tropical Indian and Pacific oceans, with exceptions in the Humbolt and California upwelling regions where warmer 
biases are found. The REF simulation also exhibits a slight cold tongue bias in the central equatorial Pacific, but this bias is very limited compared to many other CGCMs. The SSTs in the Atlantic are much less realistic, with a strong warm bias (over $3^{\circ} \mathrm{C}$ ) in the eastern equatorial and Benguela regions, a problem found in many state-of-the-art CGCMs (Richter et al. 2014).

To study in a common framework, the interactions of the tropical Indian and Atlantic oceans with ENSO, a partial coupled configuration of the model is used, with full coupling everywhere and no flux corrections, except in a specific area (e.g. the tropical Atlantic or Indian oceans), where model SSTs are nudged to a daily varying SST climatology obtained from the control run or observations, following the protocol described in Luo et al. (2005a). The method essentially modifies the non-solar heat flux provided by the atmosphere to the ocean by adding a correction term that scales with the SST error of the model. For example, if the model SST is too warm we decrease the heat flux. The damping constant used is $-2400 \mathrm{~W}$ $\mathrm{m}^{-2} \mathrm{~K}^{-1}$ and this large feedback value is applied between $30^{\circ} \mathrm{S}$ and $30^{\circ} \mathrm{N}$ in each domain. This value corresponds to the 1-day relaxation time for temperature in a 50-m ocean layer. A Gaussian smoothing is finally applied in a transition zone of $5^{\circ}$ in both longitude and latitude at the limits of the SST restoring domains. This large correction, using daily climatology, completely suppresses the SST variability in each corrected region.

First, we perform two 110 years sensitivity experiments (named FTIC and FTAC hereafter), where the model SSTs in the tropical Indian and Atlantic oceans are nudged to the SST climatology obtained from the REF simulation. These two experiments are initialized with the same initial conditions as REF in order to allow a direct comparison between the different simulations. Thus, in these experiments there are no change in the Indian or Atlantic SST mean state and seasonal cycle compared to the REF simulation, but SST interannual variability is suppressed in the corrected region. In order to assess the robustness of our results with respect to the SST biases of the model (especially for the tropical Atlantic where the model's SST biases are particularly significant in REF), two additional experiments, named FTIC-obs and FTAC-obs, were also conducted in which the SST damping is applied

211 towards a daily climatology computed from the AVHRR only daily Optimum Interpolation 212 SST (OISST) version 2 dataset for the 1982-2010 period (Reynolds et al. 2007). These 213 simulations have a length of 50 years. In these runs, the large feedback value applied fully 
removes the SST biases with respect to the observed SST climatology in addition of 215 suppressing the SST variability in the restoring domain. It is important to keep in mind that 216 the main focus of these two new experiments will be again to delineate, at the first order, if 217 ENSO is significantly different with or without inclusion of the tropical Indian or Atlantic 218 SST variability in the coupled simulation. In particular, we will not discuss in details the changes of the Pacific mean state and variability induced specifically by the correction of the SST biases in the Indian and Atlantic Oceans in the FTIC-obs and FTAC-obs runs. Table 1 summarizes the specifications of the different sensitivity experiments used here. Finally, in the following analyses, the first 20 years of the REF, FTIC and FTAC, and the first 10 years of FTIC-obs and FTAC-obs have been excluded due to the spin-up of the coupled model.

\section{2.b Maximum Covariance Analysis}

To trace the mechanisms governing the ENSO modifications in our set of experiments, we use the Maximum Covariance Analysis (MCA) approach described in Masson et al. (2012). In short, MCA describes the linear relationships between two fields by estimating the covariance matrix between these two fields and computing the Singular Value Decomposition (SVD) of this covariance matrix for defining some pairs of spatial patterns, which describe a fraction of the total square covariance (Bretherton et al. 1992). The MCA results in spatial patterns and time series. The $k$ th Expansion Coefficient (EC) time series for each variable is obtained by projecting the original monthly anomalies onto the $k$ th singular vector of the SVD of the covariance matrix. Using the ECs from the MCA, two types of regression maps can be generated: the $k$ th homogenous vector, which is the regression map between a given data field and its $k$ th EC, and the $k$ th heterogeneous vector, which is the regression map between a given data field and the $k$ th EC of the other field. The $k$ th heterogeneous vector indicates how well the grid point anomalies of one field can be predicted from the $k$ th EC time series of the other field. The chosen geographical domain for the various MCA computations covers the Pacific Ocean (defined in the area $30^{\circ} \mathrm{S}-30^{\circ} \mathrm{N}$ and $120-290^{\circ} \mathrm{E}$. Changing the latitude boundaries of this domain yields leading spatial patterns of variability that are almost similar and did not change the main results presented in section 3.

The Square Covariance Fraction (SCF) is a first simple measure of the relative importance of each mode (e.g. of each singular triplets of the covariance matrix between the two fields) in 
fields and the Normalized root-mean-square Covariance (NC), introduced by Zhang et al. 248 (1998), indicate how strongly related the coupled patterns are. These statistics will be used in section 3 to assess the strength of various atmosphere-ocean feedbacks in the different experiments.

\section{ENSO statistics, feedbacks and evolution}

3.a ENSO statistics in observations and REF

255

The difference between the observed and simulated spatial patterns of SST variability is shown in Fig. 1d. As in observation, the maximum of SST variability in REF is found in the central equatorial Pacific Fig. 1c. This maximum is slightly weaker than observed (up to $0.2^{\circ} \mathrm{C}$ ), but is not shifted westward as in many other CGCMs, thanks to the coupling method described in Luo et al. (2005b). REF also shows some discrepancies with observations in the eastern Pacific. The SST variability is overestimated over the southeast Indian Ocean, particularly along the Java-Sumatra coast, which is one of the centers of the IOD. On the other hand, the SST variability is significantly reduced over the southeast Atlantic Ocean. This is consistent with the strong SST biases in the tropical Atlantic mean state (Fig. 1b).

In order to provide a quantitative assessment of the tropical SST variability, the SST standarddeviations of the Niño-34, IOB, IOD indices and the equatorial Atlantic mode (defined by the classical ATL3 index) in observations and REF are shown in Table 2. As noted before, REF has a slightly lower Niño-34 SST variability than observed. In agreement with Terray et al. (2012), standard-deviation of the IOD index is much stronger than in observations, but the amplitude of the IOB is realistic. Finally, the simulated ATL3 SST variability is significantly reduced. These important biases affecting the equatorial Indian and Atlantic variability are unfortunately very common in current coupled models and are related to an erroneous representation of the Bjerknes, wind-evaporation-SST and cloud-radiation-SST feedbacks, 
which govern the evolution and amplitude of the IOD and equatorial Atlantic modes (Liu et al. 2014; Li et al. 2015; Richter et al. 2014; Kucharski et al. 2015).

We now examined the seasonal dependence of ENSO SST variability (Fig. 2a). The monthly standard deviation of Niño-3.4 SSTs is the highest from November to February and is about $1-0.9^{\circ} \mathrm{C}$ in the control simulation and $1-1.1^{\circ} \mathrm{C}$ in observations. The lowest standard deviations are observed during boreal spring in both observations and REF, suggesting that the model reproduces a reasonable phase-locking to the annual cycle and that El Niño onset usually occurs during boreal spring as observed. The results concerning the nudged experiments will be discussed below (see section 3.b).

In order to document how the ENSO frequency is simulated, power spectrum analysis is used (Fig. 2b). The spectral density for the observations is estimated from the HadISST1.1 dataset for the period 1900-2012 after removal of the seasonal cycle and trend. A similar preprocessing was done for the different simulations. As expected, the dominant period for the observed Niño-3.4 SST index is about 4 years with a broad spectrum between 2 and 6 years. The Niño-3.4 SST spectrum in REF is highly realistic with a similar broad spectral peak. Furthermore, the simulated ENSO spectrum is always inside the $99 \%$ confidence interval estimated from the observed spectrum (dashed lines in Fig. 2b). This is again a distinctive feature of SINTEX-F2 compared to many CMIP5 models, which still fail to reproduce the observed ENSO frequency (Jha et al. 2013). This good agreement between the observed and simulated ENSO power spectra provides confidence to use SINTEX-F2 to investigate the changes of ENSO frequency associated with Indian or Atlantic oceans variability as well as the mechanisms connecting the variability in the three basins, in the next sections.

Figure 3 shows the observed and simulated correlations of tropical SSTs with the Niño-3.4 SST during December-January (DJ hereafter), when ENSO is in its mature phase. The ENSOdeveloping (decaying) phase is defined as a prior (posterior) period of the ENSO mature phase (DJ). The years for the ENSO-developing and decaying phases will be denoted "year0" and "year+1", respectively. Similarly, we will use the notation "year-1" to denote the year preceding the ENSO-developing year in REF. The modeled El Niño has its onset during the boreal spring as observed. The simulated spatial pattern of extra-tropical SST anomalies in the 
312 North and South Pacific before or at the ENSO onset period matches the observations. Cold 313 SST anomalies are also observed and simulated before El Niño onset over the tropical Indian 314 and Atlantic oceans. However, these SST signals are mainly confined in the tropics in REF, 315 while they extend significantly in the southern ocean in observations. Also in the tropical 316 Atlantic Ocean, significant cold anomalies are found north of the equator in REF rather than 317 in the southern hemisphere as in observations during boreal spring and summer of year0 (Fig. 318 3).

320 It is interesting to note that, conversely to many CCGMs, the ENSO events in REF are not too 321 narrowly confined to the equator and do not extend too far to the west. Furthermore, the life 322 cycle of the ENSO events in the model, as seen from the SST anomalies, agrees well with 323 observations, exhibiting realistic teleconnections with the extra-tropics, as well as over the 324 Indian and Atlantic Oceans (Fig. 3). As an illustration, SINTEX-F2 is able to reproduce 325 realistic correlations of ENSO with IOD and IOB modes during boreal fall and winter, 326 respectively. Nevertheless, the simulated IOD starts too early, extends too far west along the 327 equator, is too strong (see Table 2) and is strongly correlated with ENSO compared to 328 observations. This is a persisting bias of the SINTEX model, which is related to the 329 overestimated strength of the wind-thermocline-SST and wind-evaporation-SST positive 330 feedbacks and a too shallow thermocline in eastern equatorial Indian Ocean during boreal summer and fall (Fischer et al. 2005; Terray et al. 2012). To a large extent, El Niño (La Niña) events tend to be accompanied by Atlantic Ocean warming (cooling) from late boreal summer onward both in observations and REF (Fig. 3). Subsequent to the El Niño mature phase, the

334 tropical Pacific SST anomalies start to decay at the beginning of year+1 and most simulated 335 El Niño events terminate before or during boreal summer of year +1 as observed (see Fig. 12 336 later).

338 In summary, SINTEX-F2 simulates well many of the ENSO statistical properties, such as the spatial pattern of tropical Pacific SST standard deviation, the ENSO teleconnections, the 340 power spectrum of Niño-34 SSTs, the seasonal phase locking of ENSO variability (Masson et 341 al. 2012). This is entirely consistent with its success in climate predictability studies (Luo et 342 al. 2005a). This good agreement provides confidence to further investigate the mechanisms 343 connecting variability in the three tropical basins with this CGCM. In particular, we now 344 carefully compare the ENSO statistics between the nudged and REF simulations. 
346 3.b ENSO statistics in the nudged experiments

347 The exclusion of the Atlantic or Indian Ocean variability has a non-significant impact on the 348 mean SST in the other tropical basins and, especially, in the tropical Pacific (Figs. 4a, c). 349 Between $40^{\circ} \mathrm{S}-40^{\circ} \mathrm{N}$, the differences of the FTIC and FTAC nudged experiments with REF 350 are most often smaller than $0.05^{\circ} \mathrm{C}$ in amplitude inside, but also outside the nudging regions. 351 In any case, these values are much smaller than the SST differences with the observations 352 (Fig. 1b). This statement is also valid for the monthly SST climatologies computed from 353 FTIC and FTAC (not shown). These results must be kept in mind when we discuss the 354 changes of ENSO variability in these nudged experiments since these changes cannot be 355 explained by differences in the Pacific mean state or seasonal cycle in these simulations 356 compared to REF.

However, these conclusions are not valid when we consider the FTIC-obs and FTAC-obs experiments (Figs. 4b, d). Interestingly, the corrections of the tropical Indian (Atlantic) warm SST biases in these experiments have a significant influence on the mean state of the other basins and, generally, lead to a colder mean state and a systematic reduction of the warm SST bias in the tropics. This is especially true for the western-central Pacific, but also for different upwelling regions such as the eastern equatorial Atlantic in FTIC-obs (Fig. 4b) or the South American and East African coasts in FTAC-obs (Fig. 4d). These nudged experiments also show a slight warming in the central-east equatorial Pacific compared to REF. Thus, removing SST biases in the Atlantic or Indian oceans, surprisingly, improves the simulated Pacific mean state by inducing a cooling of the Indo-Pacific warm pool and a slight reduction of the cold tongue bias in the central-east equatorial Pacific. This is consistent with the works of Kucharski et al. (2011) or Chikamoto et al. (2012) in a global warming context, which suggest that the long-term Atlantic or Indian warming trends have played a role in reducing the eastern Pacific warming. Similarly, the interpretation here is that reduction of the Indian or Atlantic tropical heating associated with the correction of the warm SST biases in FTICobs and FTAC-obs promotes changes in the Walker circulation and induces an El Niño-like change in the equatorial Pacific (figures not shown). This modest improvement of the equatorial Pacific mean state in both the FTAC-obs and FTIC-obs experiments may also have a significant impact on the simulated ENSO since many aspects of ENSO variability, 
including its seasonal phase-locking properties, are largely dependent on the tropical Pacific mean state.

Figs. 4e-h first confirm that almost all the tropical Indian (Atlantic) SST variability has been removed in the nudged experiments. Outside the corrected region, the SST variability changes in the nudged experiments are mainly found in the tropical Pacific. A large increase of ENSO variability is found when the Indian Ocean variability is excluded (Figs 4e, f), but only a marginal increase when the Atlantic Ocean is decoupled (Figs. 4g, h). The increase of the standard deviation is as large as $0.3-0.5^{\circ} \mathrm{C}$ in the central-eastern equatorial Pacific for the Indian Ocean decoupled runs. This result is opposite to the earlier findings (Yu et al. 2002, 2005; Wu and Kirtman 2004), but agrees well with more recent studies (Kug and Kang 2006; Dommenget et al. 2006; Jansen et al. 2009; Frauen and Dommenget 2012; Santoso et al. 2012). On the other hand, decoupling the Atlantic SST variability leads to only a very modest increase of ENSO variability, which is in contrast to some recent results (Dommenget et al. 2006; Frauen and Dommenget 2012). Another interesting result is that the increased ENSO variability is always stronger when the nudging is done toward the observed SST climatology and this increase is particularly significant in FTIC-obs.

It is well known that ENSO exhibits an asymmetric behaviour between its opposing phases (Clarke 2008). This non-linear ENSO component manifests itself with a significant positive SST skewness in the eastern equatorial Pacific (Masson et al. 2012; Roxy et al. 2014). SINTEX-F2 has difficulties in representing this positive skewness associated with ENSO as many other CGCMs (see Fig. 11 of Masson et al., 2012). However, an interesting observation is that the SST skewness increased in all the decoupled experiments, suggesting that the ENSO damping associated with the Indian and Atlantic oceans coupling affects more the El Niño than the La Niña events (figures not shown).

We are now shifting our focus to the assessment of the changes in ENSO seasonal phase locking in the nudged experiments (Fig. 2a). The peak phase of the simulated ENSO occurs in boreal winter and the minimum standard deviation is found during boreal spring in all simulations and the observations, but there are distinctive features between the nudged experiments and REF. The most striking features are (i) the increase of ENSO variability during boreal summer in nearly all the nudged experiments, (ii) the recovery of a clear and 
realistic minimum of monthly SST variability during boreal spring (e.g. April) and the so-

411 called "spring barrier" in all the nudged experiments using an observed SST climatology 412 despite of the general increase of ENSO variability in these simulations and (iii) a less 413 pronounced minimum of monthly SST variability during boreal spring in FTIC and FTAC, 414 which use a simulated SST climatology for the nudging.

416 These results suggest surprisingly that the seasonal phase locking of ENSO is partly 417 associated with its coupling to the Indian and Atlantic oceans. More specifically, we interpret 418 the recovery of a more realistic seasonal phase locking of ENSO in FTIC-obs and FTAC-obs 419 as a direct consequence of the improvement of the Pacific mean state and seasonal cycle in 420 these simulations, especially a tendency for a decreased east-west SST gradient in the 421 equatorial Pacific compared to REF (see Figs. 4b, d). This change is rather modest in Figs. 4b, $422 \mathrm{~d}$ where all the months are considered, but is much more prominent during boreal spring 423 favoring the growth of instabilities related to El Niño onset in both FTIC-obs and FTAC-obs (see Figure 14 of Prodhomme et al. 2015). Conversely, there is a substantial increase of SST variability during this crucial season in FTIC and FTAC simulations, pointing again to the significant role of the Indian and Atlantic mean SST biases for a realistic simulation of ENSO properties. All these features are consistent with the rectification of the tropical Pacific mean state in FTIC-obs and FTAC-obs, which is missing in FTIC and FTAC since the nudging is done toward the REF climatology in these runs. The modification of the seasonal phaselocking of ENSO in FTIC and FTAC experiments also suggests that boreal spring is no more the preferential season for ENSO onset or termination, pointing to a possible change of the In order to address these aspects of ENSO variability, power spectra of monthly mean Niño3.4 SST anomalies in the nudged experiments are displayed in Fig. 2b. The spectra for all the nudged experiments are outside the $99 \%$ confidence interval computed from the observed Niño-34 SST spectrum, while the spectrum estimated from REF matches the observations.

438 The ratios between the Niño-3.4 SST spectral densities in REF and the nudged experiments can be used to test the hypothesis of a common spectrum for two time series from the different experiments with an F-distribution (Fig. 5; see Masson et al. 2012 for further 441 details). All the nudged experiments show more power at longer periods compared to REF 442 and these changes are significant since their corresponding spectral ratios are below the lower 
limit of the $90 \%$ point-wise tolerance interval (computed under the assumption that the underlying spectra are the same) for periods between 8 and 10 (10 and 30) years for FTIC or FTIC-obs (FTAC and FTAC-obs). This shift to longer ENSO periods is particularly strong when the Atlantic Ocean is decoupled (Figs. 5c, d). Interestingly, if we consider the periods between 1.5 and 3 years, almost all spectral ratios also show values above the upper limit of the $90 \%$ point-wise tolerance interval, suggesting that both Indian and Atlantic oceans couplings introduce significant biennial variability in the simulated ENSO (Yu et al. 2009).

Furthermore, all these results are robust since they are found independently of the details of the nudging (e.g. if this nudging is done toward a simulated or observed SST climatology). This suggests that the turnabout of ENSO cycle is lengthened and that ENSO's recurrence may shift to lower frequencies when the coupling is turned off, especially in the Atlantic Ocean. Moreover, none of these changes can be explained by a change of the mean-state in the tropical Pacific in the case of the FTIC and FTAC experiments. Taking into account that the mature phase of ENSO still occurs during boreal winter, there are two possible, but no contradictory, explanations for these differences between the nudged experiments and the control simulation: the first is that ENSO onset occurs before boreal spring, the second is that the transition from El Niño to La Niña is much slower in the decoupled runs. This last hypothesis is consistent with the feedback mechanism proposed by Kug and Kang (2006) as far the Indian Ocean is concerned. Both explanations may also explain why the phase-locking of ENSO to the annual cycle is reduced in the FTIC and FTAC decoupled experiments (see Fig. 2a). These two hypotheses will be further examined in the next sections (i.e. in sections 4 and 5).

\section{3.c ENSO feedbacks in the nudged experiments}

A lead-lag correlation analysis between the simulated $20^{\circ} \mathrm{C}$ isotherm depth (20d hereafter) and the DJ Niño-3.4 SSTs further supports the finding that decoupling the Atlantic or Indian oceans leads to a longer ENSO cycle with significant changes of oceanic adjustment associated with the ENSO cycle (Fig. 6). We only show the results from the FTIC and FTAC experiments for conciseness and because the simulated changes cannot be explained by changes in the Pacific mean state in these experiments (Figs. 4a, c). However, similar results are obtained from the FTIC-obs and FTAC-obs experiments. 
The simulated 20d anomaly in the western and central (eastern) Pacific is significantly and positively (negatively) correlated with the DJ Niño-3.4 SSTs when the former leads the latter by about 2 years in all the simulations (Fig. $6 * 1$ nd row*). This feature is consistent with the delayed oscillator and recharge oscillator theories in which subsurface ocean preconditioning is crucial for the development of El Niño (Jin 1997; Clarke 2008). Interestingly, a similar correlation pattern is found when the 20d leads the Niño-3.4 SSTs by about one year in REF, but not in FTIC and FTAC (Fig. $6 * 2$ nd row*). When the Indian or Atlantic oceans are decoupled, the western Pacific positive heat content anomalies have already propagated eastward and are found in the central and eastern equatorial Pacific one year in advance of the peak of the Niño-3.4 SST anomaly. This suggests that El Niño has already started in FTIC or FTAC, but not in REF. During El Niño mature phase, the correlation maps have similar patterns and amplitudes (Fig. $6 * 3$ nd row*). However, the correlation patterns when the DJ Niño-3.4 SSTs lead the 20d by one year confirm that the Indian or Atlantic oceans coupling fastens the transition from El Niño to La Niña in REF. Significant negative heat content anomalies are already well established in the eastern Pacific and the extra-tropical heat discharge completed during the boreal fall following the peak ENSO phase in REF. On the other hand, the eastern Pacific positive heat content anomaly is not collapsed and the discharge is still active in FTIC or FTAC (Fig. $6 * 4$ nd row*). This is consistent with the shift to lower frequencies in the simulated ENSO spectra in the nudged experiments.

ENSO evolution results from a number of ocean-atmosphere feedbacks (Jin et al. 2006; Guilyardi et al. 2009). Thus, evaluating the balance and strength of these feedbacks may lead to a better understanding of the mechanisms, which are important for the significant modifications of the simulated ENSO characteristics in the nudged experiments. Here, we focus specifically on the positive Bjerknes and thermocline feedbacks in the different experiments with the help of different MCAs (see section 2.b).

Figures $7 \mathrm{a}, \mathrm{b}$ display the leading modes derived from a MCA analysis of the SST and zonal wind stress (USTR hereafter) anomaly fields over the Pacific Ocean for the REF simulation. In the terminology of Bretherton et al. (1992), the fields presented in Figs. 7a, b are homogenous (covariance) pattern for SST and heterogeneous pattern for USTR. The leading MCA modes for these variables in the nudged experiments have similar spatial structures, but with spatial loadings of slightly greater amplitude (especially for FTIC and FTIC-obs), and 
are thus not shown here. This MCA is useful to measure the strength of the Bjerknes feedback and, more particularly, the intensity of the wind response to SST anomalies in the central and eastern Pacific (Clarke 2008).

As expected, the SST homogenous pattern represents the peak phase of El Niño with warm SST anomalies along the equator in the central and eastern Pacific and the two cold branches of the traditional "horseshoe" pattern over the western Pacific (Fig. 7a). The corresponding heterogeneous USTR pattern features a westerly anomaly in the western and central equatorial Pacific, and a weaker easterly anomaly to the east (Fig. 7b). This wind response is reminiscent of a Gill-Matsuno response to the warm SST anomaly in the central and eastern Pacific in Fig. 7a.

In ENSO dynamics, another key element is the thermocline response to the USTR anomaly in the equatorial Pacific (Wyrtki 1975, Clarke 2008). To explore how this ocean-atmosphere interaction is modulated in the different experiments, we show the leading MCA mode from the covariance matrix between USTR and 20d anomalies for REF in Figures 7c and d. Again, we only present the results for REF because the leading MCA modes in the nudged experiments have similar spatial patterns (figures not shown). In all the experiments, the heterogeneous $20 \mathrm{~d}$ pattern describes a zonally tilting mode between western and centraleastern tropical Pacific (Fig. 7d). The associated homogeneous USTR pattern is exactly similar in structure to the zonal wind stress pattern from the SST-USTR MCAs discussed above. That is the USTR pattern in Figs. 7b and c corresponds to the peak phase of El Niño and illustrates that the zonal tilt of the thermocline across the equatorial Pacific reacts quickly to wind stress anomalies in the western-central Pacific, partly in the form of ocean Kelvin waves (Clarke 2008).

Furthermore, combining this coupled 20d-USTR mode with the USTR-SST mode leads to the following interpretation, which is embedded in the two diagnostic equations of the recharge oscillator model (Jin 1997; Burger et al. 2005): the eastern and central equatorial Pacific warming, which is observed during the peak phase of El Niño, sets up an anomalous wind stress anomaly in the western-central Pacific through a Gill-type response. This wind stress anomaly, in turn, influences the east-west gradient in thermocline depth as the warm water flows eastward. This leads to a weaker equatorial Pacific SST gradient and, finally, results in 
a positive wind-thermocline-SST feedback in which SST gradients trigger anomalous winds and these winds amplify the initial SST gradients.

Tables 3 and 4 present summary statistics for the MCAs, including the SCFs and NCs for the leading modes in the various MCA expansions and the correlation $(r)$ between the EC time series of the left and right fields. These statistics are useful to investigate the strength of this positive wind-thermocline-SST feedback in the different experiments. First we note that the leading modes of the MCAs between SST, USTR and 20d account for most of the SCF between these variables in the different experiments and are well separated from the lower MCA modes in terms of described SCF (Tables 3 and 4). Secondly, despite the strong similarity of the spatial patterns of the leading SST, USTR and 20d MCA modes in each experiment, the coupling strength between these modes is strikingly different depending on the activation of the Indian and Atlantic oceans coupling.

The SCF/NC/r for the first SST-USTR MCA mode of FTIC are 74/13/0.76 compared to 63/10/0.74 for REF (Table 3). Moreover, this first MCA mode accounts for 39\% (7\%) of the SST (USTR) variance in FTIC, but for only 30\% (6\%) in REF. Much stronger results are obtained for both the SCF/NC/r coupling coefficients and (SST and USTR) explained variances in FTIC-obs consistent with the highly significant increase of ENSO amplitude in this experiment (e.g. see Figs. $4 \mathrm{f}$ and 5b). The comparison of the FTAC, FTAC-obs and REF summary statistics gives similar results with a stronger SST-USTR coupling when the Atlantic Ocean is decoupled (Table 3). Thus, the Bjerknes feedback explains a larger fraction of the covariance between SST and the zonal wind stress in the nudged experiments. Similarly, the leading USTR-20d MCA mode captures $61,73,68,75 \%$ and $69 \%$ of the total SCF in REF, FTIC, FTIC-obs, FTAC and FTAC-obs, respectively (see Table 4). This mode explains also more than 27, 28, 25 and 27\% of the total variance of $20 \mathrm{~d}$ in FTIC, FTIC-obs, FTAC, FTAC-obs, respectively, but only 17\% in REF. The NC and $r$ statistics are again stronger in the decoupled experiments. Looking more carefully to the explained variances of the different variables displayed in Tables 3 and 4 , an interesting observation is that the increase of explained variances is particularly important for 20d and SST, but less significant

571 for USTR in the decoupled experiments. In the USTR-20d MCA (see Table 4), the explained 572 variance of USTR for FTAC-obs (6.1\%) is even less than the one found for REF (6.4\%), but 573 the corresponding explained variance of $20 \mathrm{~d}$ is still much higher in FTAC-obs $(27.8 \%)$ 
compared to REF (17.5\%). This suggests that the thermocline feedback is particularly efficient when the Indian and Atlantic oceans are decoupled, a finding consistent with the results of Santoso et al. (2012).

In summary, the overall wind-thermocline-SST feedback in the equatorial Pacific is much more active when the Indian and Atlantic oceans are decoupled. This finding reconfirms that ENSO behavior is different in the nudged experiments.

\section{ENSO onset phase}

To further understand possible mechanisms leading to changes in ENSO properties in the Indian and Atlantic oceans decoupled runs, we focus specifically on the ENSO onset phase in this section.

In REF and observations, weak cold SST anomalies extending from the eastern equatorial Pacific toward the dateline are found 9 months before the ENSO peak, a structure consistent with the decaying phase of La Niña and the fact that ENSO is partly a standing oscillation in the tropical Pacific (Fig. 3). Interestingly, during February-March, the warmest SST anomalies in the Pacific occur off the equator. Simulated Sea Level Pressure (SLP), precipitation and surface wind anomalies during boreal spring regressed onto the Niño-3.4 SST during DJ (at the end of year0) are displayed in Figure 8a. These regression patterns suggest a significant connection between El Niño onset and the mid-latitude North Pacific variability in REF, which is consistent with the "Seasonal Footprinting Mechanism" (SFM) and the "Pacific Meridional Mode" (PMM) discussed by Vimont et al. (2003) and Chang et al. (2007), respectively. More specifically, a north-south anomalous SLP dipole is found over the central North Pacific during DJ, which induces a significant weakening of the northeasterly trade winds and the emergence of a boomerang warm SST structure in the tropical North Pacific via changes in wind-induced latent heat flux during the following months (Figs. 3 and 8a, b). These warm SST anomalies intrude into the deep tropics, displace the Inter-Tropical Convergence Zone (ITCZ) northward and promote southwesterly surface wind anomalies in the western equatorial Pacific from late boreal winter to spring of year0 (Fig. 8b). These equatorial westerlies are connected to the anomalous westerlies in the central 
606

607

608

609

610

611

612

613

614

615

616

617

618

619

620

621

622

623

624

625

626

627

628

629

630

631

632

633

634

635

636

637

638

North Pacific subtropics; moreover both are part of a larger cyclonic flow centered in the North Pacific (Fig. 8a). This pattern resembles the anomalous zonal wind field associated with positive phase of the PMM, which is a significant ENSO precursor 7-9 months prior to El Niño events in both observations and SINTEX-F2 (Boschat et al. 2013). They also support the idea that the North PMM is an efficient ENSO trigger via equatorially trapped wave propagation in REF as in observations (Chang et al. 2007).

This suggests that the dominant non-ENSO variability influencing ENSO onset in REF is the PMM, but this does not rule out the possible impact from the Atlantic or Indian oceans (Boschat et al. 2013). In fact, significant cold SST and positive SLP anomalies are also observed during boreal spring (and before) in both the Indian and Atlantic oceans (Figs. 3 and 8a). This SST pattern may result from the previous ENSO phase (Kug and Kang 2006) or, alternatively be linked to subtropical variability independent from ENSO (Terray 2011; Boschat et al. 2013). In order to address the relative importance of these Indian and Atlantic SST signals in ENSO onset, we now focus on the decoupled experiments.

Figure 9 displays the lag correlations between the DJ Niño-3.4 SSTs (at the end of year0) and the SST fields during year-1 in FTIC and FTAC. First, we note that Indian and Atlantic couplings seem to be critical for the timing of the ENSO onset, since in the decoupled runs this onset occurs several months before compared to REF (e.g. during year-1). Significant positive SST anomalies exist in the equatorial central Pacific as soon as August-September of year-1 in FTIC and FTAC. These warm SST anomalies slowly move eastward and extend meridionally during the following seasons. This illustrates the occurrence of long-lasting El Niño episodes in the decoupled runs, partly due to a very slow developing phase, which last for several months. This is in great contrast with REF in which the El Niño onset is a very fast process and the SST El Niño pattern is fully developed in June-July of the same year (Fig. 3a). FTIC-obs and FTAC-obs exhibit a very similar ENSO development, which further attests of the robust impact of Indian and Atlantic coupling on the ENSO onset and its timing (figures not shown).

We now illustrate how ENSO is initiated in the FTIC and FTAC experiments with the help of Figs. 10 and 11. During February-March of year-1, the correlation patterns suggest the existence of La Niña conditions in the tropical Pacific with significant cold (warm) anomalies 
in the eastern (western) equatorial Pacific, a positive phase of the Southern Oscillation and

640 enhanced easterlies over the equatorial Pacific (Figs. 9, 10 and 11). Consistent with these

641 zonal wind anomalies, there is a strong zonal contrast in the heat content over the tropical

642 Pacific basin during February-March of year-1 and this positive heat content in the western

643 Pacific seems to be a robust and significant precursor of El Niño nearly two years in advance

644 in FTIC and FTAC (Fig. 6).

646 During April-May, this La Niña-like pattern fades away in both decoupled experiments. It is 647 interesting to observe that there are no clear links during boreal spring of year-1 (or year0)

648 between the cyclonic flow in the North Pacific, the westerly wind anomalies over the western 649 equatorial Pacific and the amplitude of the ongoing El Niño event, which will peak at the end 650 of year0 (Figs. 10 and 11). This is in sharp contrast with the evolution in REF where the SFM 651 over the North Pacific plays a key role in El Niño onset during year0 (Fig. 8). Closer 652 inspection reveals that westerly wind anomalies appear over the western equatorial Pacific 653 from boreal summer of year-1 in association with El Niño onset in the decoupled runs (Figs. 65410 and 11). But these wind anomalies evolve independently of the North Pacific extra-tropical 655 forcing and are not related to the SFM in both FTIC and FTAC, contrary to what is observed 656 in REF.

658 We first focus on the possible origin of the persistent positive westerly wind signal from June 659 of year-1 onward in the FTIC experiment (Fig. 10). This wind variability over the far western 660 Pacific is significantly associated with SST anomalies over the Western North Pacific (WNP), 661 namely positive SST anomalies in the western and central equatorial Pacific and negative SST 662 anomalies over the northwest Pacific from June of year-1 onward in the FTIC experiment (see 663 Fig. 9a). A similar SST pattern is seen in FTIC-obs (figure not shown). This suggests that this 664 wind variability over the western equatorial Pacific is mainly driven by the local SST related 665 to the previous La Niña episode (Weisberg and Wang 1997). However, this does not exclude 666 the role of other remote factors such as the mid-latitude atmospheric variability over the South 667 Pacific or even the cold SST and positive SLP anomalies over the tropical Atlantic during 668 boreal summer of year-1 since these two other signals exhibit a highly significant statistical 669 association with the amplitude of the ongoing El Niño event (Fig. 10). We investigate these 670 aspects next. 
672 We first examine the potential role of the South Pacific atmospheric variability on the ENSO 673 development in FTIC. As displayed in Fig. 10, an expanded trough emerges over the South 674 Pacific, extends into the deep tropics and promotes westerly wind anomalies over the western 675 equatorial Pacific during the austral winter of year-1 in FTIC. This mid-latitude South Pacific 676 SLP variability is reminiscent of the first Pacific-South American (PSA) pattern, which is 677 dominant during the developing phase of ENSO in observations (Jin and Kirtman 2009; 678 Terray 2011; Ding et al. 2014). Ding et al. (2014) suggest that this PSA pattern imparts a 679 structure of SST anomalies over the South Pacific analogous to the PMM in the Northern 680 Hemisphere through the associated wind and latent heat anomalies. This South PMM is, in 681 turn, able to force zonal wind anomalies along the equator and has an influence on ENSO 682 development consistent with the SFM hypothesis for the Southern Hemisphere. Interestingly, the SST correlation patterns during boreal summer of year-1 in FTIC experiment (see Fig. 9b) are reminiscent of this South PMM. This supports the idea that the South Pacific variability during austral winter may also play a role in the El Niño onset in FTIC.

However, this does not exclude other important contributing factors such as the cold tropical Atlantic SSTs during boreal summer of year-1 through a modulation of the Atlantic-Pacific Walker circulation (Ding et al. 2012; Polo et al. 2014). From April to July of year-1, cold SST anomalies cover nearly the whole Atlantic basin in the FTIC experiment (Fig. 9a). Associated with these cold Atlantic SSTs there are local positive SLP anomalies (and also negative rainfall anomalies) over the equatorial Atlantic (Fig. 10). The corresponding diabatic cooling modulates the Walker circulation by inducing convergent (divergent) motion over the tropical Atlantic (western and central Pacific) at $200 \mathrm{hPa}$ (figure not shown). This is in agreement with the high (low) SLP anomalies in the tropical Atlantic (western-central Pacific) during boreal summer of year-1 (Fig. 10). The induced low pressure and ascending motion anomalies over the western Pacific may promote convective activity and westerly wind stress anomalies there (Fig. 10). This is consistent with the mechanism described by Fonseca et al. (2009), Ding et al. (2012) or Polo et al. (2014).

The main point is that all these different factors may be interrelated and collectively promote the generation of persistent low-level westerlies over the far western equatorial Pacific from June of year-1 onward, which may be responsible for the ENSO onset in FTIC experiment since these low-level wind anomalies over the western equatorial Pacific are optimally 
situated to influence the generation of eastward propagating oceanic Kelvin waves (Kug et al. 2010). Forced by this westerly wind stress, the equatorial Pacific thermocline slope is decreased, with shoaling and deepening in the west and east, respectively, during year-1 (see Fig. 6). At the end of year-1, these wind stress, thermocline and SST anomalies are further amplified by the Bjerknes positive feedback, sustaining the development of El Niño-like anomalies during year0 in FTIC.

In the Atlantic decoupled experiments, the persistent westerly wind signal over the western equatorial Pacific is seen from August of year-1 onward, e.g. 2 months later than in the Indian decoupled runs (Figs. 10 and 11). However, again these wind changes and their timings are critical for the simulated ENSO variability in FTAC (Fig. 9b). As a result, the western Pacific positive heat content anomalies migrate to the east during boreal fall and cover the whole equatorial Pacific at the end of year-1 in FTAC (Fig. 6). This may trigger the ENSO onset in the Atlantic decoupled runs, consistent with SST correlation patterns during year-1 displayed in Fig. 9b. A closer examination of Figure 9b points again to the key-role of a dipole of SST anomalies in the WNP, with negative SST anomalies over the northwest Pacific and positive SST anomalies in the western equatorial Pacific, for sustaining the local low-level cyclonic circulation from June onward (Weisberg and Wang 1997; Wang et al. 2012). This dipole of SST anomalies has a very similar pattern in the Indian and Atlantic decoupled runs, but its timing is different with a lag of two months in the Atlantic decoupled runs. Since the westerly wind anomalies also appear over the western equatorial Pacific with a lag of two months in the Atlantic decoupled runs, this strongly supports the idea that the SST dipole over the WNP is responsible for the emergence of the westerly zonal wind anomalies through coupled local interactions in the different decoupled runs (Weisberg and Wang 1997; Wang et al. 2012).

The North PMM plays a vital role in ENSO onset during year0 in the REF simulation. In this section, we have presented evidences that strongly support the idea that Indian and Atlantic SST variability is essential for this relationship between the PMM and ENSO onset in REF since ENSO onset occurs in year-1 in all the decoupled experiments and are no more related to the North PMM during boreal spring.

\section{ENSO decaying phase}


738 We now focus on the role of Indian and Atlantic SSTs during the decaying phase of ENSO.

739 Since the results are again similar between FTIC and FTIC-obs (or FTAC and FTAC-obs), we 740 will present only the results from FTIC and FTAC experiments.

742 Figure 12 displays the lag-regressions of bi-monthly SST fields from April to November of 743 year+1 with the DJ Niño-3.4 SST time series during the previous boreal winter. First, we find 744 that the ENSO-related SST anomalies in the equatorial Pacific last longer in the decoupled 745 experiments. This is consistent with the time evolution of $20 \mathrm{~d}$ shown in Fig. 6, as well as with 746 previous studies (Kug and Kang 2006; Dommenget et al. 2006; Frauen and Dommenget 747 2012; Santoso et al. 2012). In REF, negative SST anomalies appear first over the central 748 equatorial Pacific in June-July of year+1 and persist afterward (Fig. 12). By contrast, high 749 positive SST anomalies are noted in the same area and period in FTIC, while nearly 750 climatological SST values are simulated in the central equatorial Pacific from June-July of 751 year+1 onward in FTAC. Thus, the SST evolution in FTAC is intermediate between the two 752 contrasting SST evolutions in REF and FTIC simulations. This suggests that Indian Ocean 753 SSTs may have a stronger impact on ENSO during its decaying phase. The warm ENSO754 related SST anomalies over the tropical Atlantic (Indian) Ocean from April-May to October755 November of year+1 have the same amplitude or are slightly stronger in the FTIC (FTAC) 756 compared to REF, especially at the end of year+1. However, it is intriguing to observe that 757 this persisting SST variability in the Atlantic or Indian basins in FTIC and FTAC runs, 758 respectively, are not sufficient to lead to cold SST anomalies in the Pacific and a rapid demise 759 of the ENSO events as in REF (Fig. 12).

761 To understand better why the equatorial Pacific SST anomalies last longer after the ENSO 762 peak in the decoupled experiments, the evolution of bi-monthly mean 10-m zonal wind 763 anomalies obtained through regression onto DJ Niño-3.4 SST in the control and decoupled 764 runs are shown in Figure 13.

766 During April-May of year+1, the regressed surface zonal wind patterns in all the simulations 767 are very similar with enhanced easterly (westerly) zonal wind anomalies over the western 768 (central and eastern) equatorial Pacific. However, from June-July onwards, the western 
Pacific-enhanced easterly anomalies fade away in the decoupled runs, but persist in REF, which ultimately lead to the rapid demise of eastern Pacific warm heat content anomalies and a strong damping of the equatorial Pacific SST anomalies in REF (Figs. 6 and 12). These anomalous easterlies over the western equatorial Pacific can induce an upwelling thermocline anomaly propagating eastward that fastens the transition from El Niño to La Niña in REF (Kug and Kang 2006). In contrast, the transition to a normal Pacific state is further delayed by several months in both the FTIC and FTAC experiments, as westerly wind anomalies are stronger, last longer over most of the west and central equatorial Pacific and the thermocline remains deep in the eastern Pacific (Figs. 6 and 13). This is consistent with the enhanced Bjerknes feedback in the decoupled runs (Tables 3 and 4). In other words, the 20d, SST and surface zonal wind regression maps clearly show the role of the western Pacific wind anomalies in hastening the transition from El Niño to La Niña in REF compared to the nudged experiments.

Interestingly, despite of the absence of SST variability, strong and persistent equatorial easterlies are also found from April to November of year+1 over the nudged region in both FTIC and FTAC (Fig. 13). All these features are in accordance with the slowdown of the Walker circulation during a long lasting El Niño when the convection and the uprising branch of the Pacific Walker circulation are shifted to the east during an extended period. Also, in agreement with the anomalous SST equatorial gradient in the Atlantic Ocean from June to November of year +1 , enhanced surface easterly wind anomalies are simulated over this basin in FTIC (see Figs 12 and 13).

The $200 \mathrm{hPa}$ wind and velocity potential regression maps during year+1 onto the Niño-3.4 SST index demonstrate that the above features are related to important changes in the Walker circulation over the Atlantic and Indian oceans in FTIC and FTAC, respectively (Fig. 14). Negative rainfall anomalies or much weaker positive anomalies are observed over most of the nudged region in FTIC and FTAC experiments compared to REF (figure not shown). Positive rainfall anomalies are restricted to a rather small western equatorial area inside of the nudged region consistent with the enhanced equatorial easterlies simulated near the surface (Fig. 13). Thus, over the nudged region in FTIC and FTAC, the absence of SST variations induces

800 subsidence in the atmospheric column, enhanced convergence in the upper atmosphere and 801 strong westerly anomalies at $200 \mathrm{hPa}$ during year+1. 
803 In turn, the velocity potential regression maps demonstrate that the western Pacific low-level

804 wind changes are related to modulations of Pacific Walker circulation induced by the absence

805 of the Indian or Atlantic SST anomalies in the nudged runs. Strong positive (negative)

806 velocity potential anomalies are found at $200 \mathrm{hPa}$ over the Indian-Maritime Continent

807 (Pacific) region from late spring to early boreal winter in FTIC and FTAC (Fig. 14). The 200

$808 \mathrm{hPa}$ wind anomalies are easterly over the central equatorial Pacific, especially in FTIC. In

809 REF, these upper velocity potential and wind anomalies are much weaker, quickly fade away

810 after April-May of year+1 and are replaced by negative (positive) velocity potential

811 anomalies over the Maritime Continent (central Pacific). This suggests again a fast demise of

812 the El Niño conditions and a return to normal conditions from late boreal summer or fall of 813 year+1 in REF.

814

815 In other words, the positive Indian or Atlantic SSTs induce anomalous heating in the 816 atmosphere through local surface heat fluxes and rainfall anomalies. The anomalous heating 817 leads to a modulation of the Walker circulation (Fig. 14). These circulation changes in turn 818 cause surface wind anomalies in the far western Pacific, which are responsible for a fast El 819 Niño to La Niña transition as described above. On the other hand, the low-level wind 820 anomalies over the central and eastern equatorial Pacific remain eastward from early spring to 821 fall of year+ 1 in the different simulations and cannot explain this fast demise of El Niño in 822 REF compared to the decoupled experiments (Fig. 13). This demonstrates the existence of a 823 very close relationship between the sign and amplitude of the zonal low-level wind over the 824 far western Pacific and the time required for a transition from the warm phase to the cold 825 phase of ENSO through the generation of oceanic-upwelling Kelvin waves that change the 826 oceanic thermocline in the whole equatorial Pacific. Next, the results also indicate that these 827 anomalous easterlies over the far western equatorial Pacific are intimately linked to the 828 existence of upward motion (or positive rainfall) anomalies to the west, especially over the 829 Maritime Continent and eastern Indian Ocean in the different simulations. The different 830 experiments highlight that vertical motion over the eastern Indian Ocean and Maritime 831 Continent is not only dependent on the local SST or Pacific SST, but also on the Atlantic 832 SST. 
834 The regressed velocity potential fields also demonstrate that the net influence on ENSO of 835 either the Indian and Atlantic SST variability is strongly dependent of what happens in the 836 other tropical basin (Fig. 14). As a first illustration, in FTIC, significant warm SST anomalies 837 and negative upper level velocity potential anomalies are simulated over much of the tropical 838 Atlantic and are stronger than in REF (Figs. 12 and 14). Despite of these highly significant anomalies, the transition from El Niño to La Niña is delayed by several months in FTIC compared to REF due to the exclusion of the Indian Ocean SST variability. In FTIC, there is no competition between the upper level divergence centers over the central Pacific and Atlantic oceans, both act in concert and promote a strong upper-level convergence into the Indian Ocean, inducing subsidence and inhibiting the local rainfall over this region and the Maritime Continent. This probably explains the very weak easterlies over the far western equatorial Pacific in FTIC experiment despite of the warm Atlantic SST anomalies.

In a similar way, in FTAC, significant warm SST anomalies are found over the tropical Indian Ocean from early boreal spring to late fall of year +1 (Fig. 12). Despite of these warm SSTs, positive upper level velocity potential anomalies and negative rainfall anomalies cover the whole Indian domain, due to the subsidence aloft directly or indirectly induced by the absence of Atlantic SST variability in FTAC (Fig. 14). This is consistent with the reduced surface easterlies over the western equatorial Pacific during the decaying ENSO phase in FTAC (Fig. 13). The direct effect is linked to the fact that the atmospheric response due to the absence of SST variability over the Atlantic may extend eastward in the Indian Ocean (Kucharski et al. 2007, 2008; Losada et al. 2010). The indirect effect is associated with the fact that exclusion of the Atlantic SST variability may affect ENSO through the Pacific-Atlantic Walker circulation (Rodriguez-Fonseca et al. 2009; Ding et al. 2012; Frauen and Dommenget 2013) and the resulting long lasting El Niño event will promote increased subsidence over the tropical Indian ocean through the atmospheric bridge (Alexander et al. 2002). However, it is difficult without further numerical investigations to determine if this reduced rainfall signal over the Indian Ocean is related to the subsidence induced directly by the atmospheric response over the Atlantic basin to the west or indirectly by the persistent El Niño conditions over the tropical Pacific, which are related to the modulation of the Atlantic-Pacific Walker circulation to the east.

\section{Conclusions and Discussion}


868 There are strong evidences of interactions between Indian, Atlantic and Pacific oceans and

869 recent studies suggest an active role of the Indian and Atlantic basins on ENSO (Kug and 870 Kang 2006; Rodriguez-Fonseca et al. 2009; Izumo et al. 2010; Luo et al. 2010; Ding et al. 871 2012; Frauen and Dommenget 2013; Boschat et al. 2013). However, the mechanisms 872 underlying these relations are not fully understood and the relative impacts of these two 873 basins remain unclear.

874

875 Thus, to better understand how the Indian and Atlantic oceans impact ENSO, we have 876 performed several long sensitivity experiments using a CGCM, which realistically simulates 877 many facets of ENSO. For each experiment, we suppressed the SST variability in either the 878 Indian or Atlantic oceans by applying a strong nudging of the SST toward a SST climatology 879 computed from a control experiment or observations. This experimental framework is the 880 same as in Frauen and Dommenget (2012), but we used a fully global CGCM, while they 881 used a hybrid model. This hybrid model does not take into account the ocean dynamics 882 outside the Pacific region and used heat flux corrections to maintain a reasonable SST 883 climatology outside the tropical Pacific. Thus, our work is a logical extension of the analysis 884 of Frauen and Dommenget (2012) since our study takes fully into account the possible 885 existence of intrinsic coupled ocean-atmosphere modes of variability in the Atlantic or Indian 886 basins, such as the IOD or the Atlantic zonal mode, which interact with ENSO (Fischer et al. 887 2005; Rodriguez-Fonseca et al. 2009; Luo et al. 2010; Ding et al. 2012) and were also 888 suggested as important ENSO precursors in recent studies (Izumo et al. 2010; Keenlyside et 889 al. 2013).

890

891 The results first suggest that both the Indian and Atlantic SSTs have a significant damping 892 effect on ENSO amplitude. The increase of ENSO variability is particularly significant when 893 the Indian Ocean is decoupled. The dominant periodicities of the simulated ENSO cycle 894 increase from about 2-5 $\mathrm{yr}$ in the control run to about 3-12 $\mathrm{yr}$ in the Indian or Atlantic 895 decoupled runs. This shift to lower frequencies is more prominent in the Atlantic decoupled 896 runs. With the help of different MCAs, we also demonstrate that the Bjerknes and 897 thermocline feedbacks are more active and are partly responsible of the ENSO changes in the 898 decoupled runs. These results are consistent with recent studies using other CGCMs 

2012).

901

902 Surprisingly, the nudged experiments toward an observed SST climatology demonstrate that 903 the simulated Pacific equatorial SST gradient, seasonal cycle and seasonal phase locking of 904 ENSO are significantly improved when SST biases are removed in the Indian or Atlantic 905 oceans. One may thus conjecture that improving model skills in simulating Indian and Atlantic oceans SST climatology may also lead to improved skill in simulating and predicting ENSO with coupled models, because they are important for a realistic ENSO seasonal phaselocking and simulation of the low-level wind variability over the western equatorial Pacific during boreal spring.

910 On the other hand, the Pacific mean state is not modified if we used the SST climatology 911 from the control run in the decoupled experiments. This demonstrates first that the correction 912 of the Pacific equatorial SST gradient discussed above is directly linked to the mean SST 913 biases in the Atlantic and Indian oceans and second that any changes in ENSO variability in 914 the decoupled runs using a simulated climatology cannot be explained by a rectification of the 915 Pacific mean state. This strongly supports the hypothesis that both the Indian and Atlantic 916 oceans interplay with the ENSO dynamics (Kug and Kang 2006; Rodriguez-Fonseca et al. 917 2009; Izumo et al. 2010; Terray 2011; Santoso et al. 2012; Ding et al. 2012; Ham et al. 2013a, 918 b).

Many of the previous studies focused on the influence of Indian and Atlantic SST variability on ENSO during the peak and decaying phases of El Niño. Moreover, to a large extent, they almost all agreed that the physical processes that allow the Indian or Atlantic oceans to influence ENSO, involve modulations of the Walker circulation and of the surface winds in

924 the western equatorial Pacific, which trigger eastward-propagating oceanic Kelvin waves 925 responsible for the turnabout of ENSO. However, the Indian and Atlantic basins may also 926 play a key-role in triggering ENSO events (Izumo et al. 2010; Terray 2011; Boschat et al. 2013; Frauen and Dommenget 2012; Ham et al. 2013a, b). Our study confirms that Indian or Atlantic SSTs influence significantly both the onset and decaying stages of ENSO events. 
930 During the decaying phase of ENSO, Indian and Atlantic SST anomalies, both in observations 931 and the control simulation, are largely forced by ENSO, and the processes we have detailed 932 during this phase, may be best described as a negative feedback on ENSO (Kug and Kang 933 2006; Ohba and Ueda 2007; Santoso et al. 2012; Dayan et al. 2014). The large agreement 934 between our CGCM results and the results of Frauen and Dommenget (2012), who used a 935 hybrid model excluding ocean dynamics outside the tropical Pacific, are consistent with this 936 interpretation. An important point of our study is however that Atlantic and Indian oceans act 937 together, and SST anomalies in one basin alone may not be the only factor controlling the 938 duration of the ENSO decaying phase. As an illustration, the strong warm anomalies over the 939 tropical Atlantic Ocean simulated during year+1 in the FTIC experiment are not sufficient to 940 fasten the El Niño to La Niña transition in the absence of Indian Ocean SST variability. This 941 is further confirmed by the results of the FTAC experiment in which the absence of Atlantic 942 SST variability counteracts the expected effects of the warm Indian Ocean SSTs on ENSO 943 during year +1 .

945 On the other hand, the changes of ENSO evolution during the onset phase in the nudged 946 experiments strongly support the hypothesis that intrinsic SST variability over the Indian and 947 Atlantic oceans does also matter for ENSO. First, the North PMM plays a vital role in the fast 948 ENSO onset during year0 in the REF simulation as in observations. This is consistent with 949 many previous studies, which have popularized SST anomalies over the North Pacific and the 950 SFM, as a key process for the development and predictability of ENSO (Vimont et al. 2003; 951 Chang et al. 2007; Boschat et al. 2013). However, our decoupled experiments demonstrate 952 that Indian and Atlantic SSTs are instrumental for this relationship between the North PMM 953 and ENSO onset in REF since the timing of ENSO onset is advanced by about 1 year and 954 ENSO has no more links with the North Pacific variability in these simulations. This supports 955 the idea that the occurrence of western Pacific wind stress anomalies and the stochastic 956 forcing of ENSO is strongly dependent on the Indian and Atlantic SSTs, a result, which is not 957 obvious from observations or a simple analysis of the control run.

959 All the Indian and Atlantic decoupled runs present the evidences that ENSO is triggered in 960 year-1, i.e. more than 1 year in advance than its peak phase, which occurs at the end of year0. 961 Decoupling the Indian and Atlantic oceans reinforces the anomalous SST gradient between 962 the subtropical and tropical western Pacific during boreal summer and fall of year-1 and 
963

964

965

966

967

968

969

970

971

972

973

974

975

976

977

978

979

980

981

982

983

984

985

986

987

988

989

990

991

992

993

994

995

ultimately impacts the low-level circulation over the western Pacific during the second half of year-1. These wind changes and their timing are critical for ENSO variability because the eastern Pacific SST is closely linked to the equatorial western Pacific wind via equatorial Sverdrup balance. As a result, the western Pacific positive heat content anomalies migrate relatively slowly to the east and cover the whole equatorial Pacific at the end of year- 1 . This triggers the ENSO onset in the Indian and Atlantic decoupled runs.

Overall from our results, the importance of the Indian Ocean on ENSO seems stronger. However, the major systematic errors of complex models (Richter et al. 2014), including the SINTEX-F2 model used here, in simulating the equatorial Atlantic climate need to be reduced before any definitive conclusion can be reached about the true forcing on ENSO induced by Atlantic SST variability. It should also be noted that the determination of the relative contribution of the subtropical Indian or Atlantic Ocean SST variability to the simulated ENSO cannot be fully addressed by the present simulations and requires additional numerical experiments. This will be addressed in a forthcoming study.

This study is based on one model and the conclusions can be model dependent. However, since SINTEX-F2 simulates a realistic ENSO variability and performs very well in ENSO forecasting exercises (Luo et al. 2005a), the results reported here are fully consistent with the hypothesis that the skill of ENSO predictions must be higher if the tropical Indian and Atlantic variability were considered. The inter-basin interactions are crucial to improve our understanding and predictability of ENSO because the timing and intensity of the low-level wind anomalies over the far western equatorial Pacific during boreal spring is highly dependent on these inter-basin interactions.

Acknowledgments: We sincerely thank the two anonymous reviewers for their comments, which help us to improve this paper. The authors gratefully acknowledge the financial support given by the Earth System Science Organization, Ministry of Earth Sciences, Government of India (Project no MM/SERP/CNRS/2013/INT-10/002) to conduct this research under Monsoon Mission. Pascal Terray is funded by Institut de Recherche pour le Développement (IRD, France) and this work was done while Pascal Terray was a visiting scientist at IITM. This work was performed using HPC resources in France from GENCI-IDRIS. 


\section{References}

997

998 999

1000

1001

1002

1003

1004

1005

1006

1007

1008

1009

1010

1011

1012

1013

1014

1015

1016

1017

1018

1019

1020

1021

1022

1023

1024

1025

1026

1027

1028

1029

1030

1031

1032

1033

1034

1035

1036

1037

1038

Alexander MA et al (2002) The atmospheric bridge: the influence of ENSO teleconnections on air-sea interaction over the global oceans. J Clim 15:2205-2231

Barnett TP (1983) Interaction of the monsoon and Pacific trade wind system at interannual time scales. Part I: the equatorial zone. Mon Weath Rev 111:756-73.

Boschat G, Terray P, Masson S (2013), Extratropical forcing of ENSO. Geophys Res Lett 40:1-7. doi:10.1002/grl.50229

Bretherton C, Smith C, Wallace J (1992) An intercomparison of methods for finding coupled patterns in climate data. J Clim 5:541-560

Burgers G, Jin F-F, Oldenborgh GJ (2005) The simplest ENSO recharge oscillator. Geophys Res Lett 32:L13706. doi:10.1029/2005GL022951

Chang P, Fang Y, Saravannan R, Li L, Seidel H (2006) The cause of the fragile relationship between the Pacific El Niño and the Atlantic El Niño. Nature 443:324-328.

Chang P, Zhang L, Saravanan R, Vimont DJ, Chiang JCH, Ji L, Seidel H, Tippett MK (2007) Pacific meridional mode and El Niño-Southern oscillation. Geophys Res Lett 34:L16608, doi:10.1029/2007GL030302

Chikamoto Y, Kimoto M, Watanabe M, Ishii M, Mochizuki T (2012) Relationship between the Pacific and Atlantic stepwise climate change during the 1990s. Geophys Res Lett. doi:10.1029/2012GL053901

Clarke AJ (2008) An Introduction to the Dynamics of El Niño and the Southern Oscillation. London: Academic Press pp 308

Clarke AJ, Van Gorder S (2003) Improving El Niño prediction using a space-time integration of Indo-Pacific winds and equatorial Pacific upper ocean heat content. Geophys Res Lett 30:1399

Dayan H, Vialard J, Izumo T, Lengaigne M (2013) Does sea surface temperature outside the tropical Pacific contribute to enhanced ENSO predictability? Clim Dyn. doi:10.1007/ s00382013-1946-y

Dayan H, Izumo T, Vialard J, Lengaigne M, Masson S (2014) Do regions outside the tropical Pacific influence ENSO through atmospheric teleconnections? Clim Dyn. doi: 10.1007/s00382-014-2254-X 

Southern Oscillation. Clim Dyn 38:1965-1972. doi:10.1007/s00382-011-1097-y

Ding R, Li J, Tseng Y-H (2014) The impact of South Pacific extratropical forcing on ENSO and comparisons with the North Pacific. Clim Dyn. doi:10.1007/s00382-014-2303-5

Dominiak S, Terray P (2005) Improvement of ENSO prediction using a linear regression model with a southern Indian Ocean sea surface temperature predictor. Geophys Res Lett 32:L18702. doi:10.1029/2005GL023153

Dommenget D, Semenov V, Latif M (2006) Impacts of the tropical Atlantic and Indian Ocean on ENSO. Geophys Res Lett 33:L11701. doi:10.1029/2006GL025871

Ebisuzaki W (1997) A method to estimate the statistical significance of a correlation when the data are serially correlated. J Climate, 10:2147-2153

Fischer A, Terray P, Guilyardi E, Gualdi S, Delecluse P (2005) Two Independent Triggers for the Indian Ocean Dipole/Zonal Mode in a Coupled GCM. J Climate 18:3428-3449. doi:10.1175/JCLI3478.1

Frauen C, Dommenget D (2012) Influences of the tropical Indian and Atlantic Oceans on the predictability of ENSO. Geophys Res Lett 39:L02706. doi:10.1029/2011GL050520

Guilyardi E, Braconnot P, Jin FF, Kim ST, Kolasinski M, Li T, Musat I (2009) Atmosphere feedbacks during ENSO in a coupled GCM with a modified atmospheric convection scheme. J Clim 22:5698-5718

Ham Y-Y, Kug J-S, Park JY, Jin F-F (2013a) Sea surface temperature in the north tropical Atlantic as a trigger for El Nino/Southern Oscillation events. Nat Geosci. doi:10.1038/NGEO1686

Ham Y-Y, Kug J-S, Park JY, Jin F-F (2013b) Two distinct roles of Atlantic SSTs in ENSO variability: north tropical Atlantic SST and Atlantic Nino. Geophys Res Lett 40:4012-4017. doi:10.1002/gr150729

Izumo T, Vialard J, Lengaigne M, de Boyer Montegut C, Behera SK, Luo JJ, Cravatte S, Masson S, Yamagata T (2010) Influence of the state of the Indian Ocean Dipole on the following year's El Niño. Nat. Geosci. 3:168-172. doi:10.1038/ngeo760

Jansen MF, Dommenget D, Keenlyside N (2009) Tropical atmosphere-ocean interactions in a conceptual framework. J Climate 22:550-567. doi:10.1175/2008JCLI2243.1

Jha B, Hu Z-Z, Kumar A (2013) SST and ENSO variability and change simulated in historical 
1082 1083

1084 1085

1086

1087

1088

1089

1090

1091

1092

1093

1094

1095

1096

1097

1098

1099

1100

1101

1102

1103

1104

1105

1106

1107

1108

1109

1110

1111

1112

1113

1114

1115

1116

1117

1118

1119

1120

1121

1122

1123

1124

1125

1126

experiments of CMIP5 models. Clim Dyn. doi:10.1007/s00382-013-1803-z

Jin FF (1997) An equatorial recharge paradigm for ENSO. Part I: conceptual model. J Atmos Sci 54:811-829

Jin F-F, Kim ST, Bejarano L (2006) A coupled-stability index for ENSO. Geophys Res Lett 33:L23708-L23718

Jin D, Kirtman BP (2009) Why the Southern Hemisphere ENSO responses lead ENSO? J Geophys Res 114:D23101. doi:10.1029/2009JD012657

Keenlyside NS, Ding H, Latif M (2013) Potential of equatorial Atlantic variability to enhance El Nino prediction. Geophys Res Lett 40:2278-2283. doi:10.1002/grl.50362

Kug J-S, Kang I-S (2006) Interactive feedback between the Indian Ocean and ENSO, J. Climate 19:1784-1801

Kug J-S, Kirtman BP, Kang I-S (2006a), Interactive feedback between ENSO and the Indian Ocean in an interactive coupled model, J. Climate 19:6371-6381

Kug J-S, Li T, An S-I, Kang I-S, Luo JJ, Masson S, Yamagata T (2006b) Role of the ENSOIndian Ocean Coupling on ENSO variability in a coupled GCM. Geophys Res Lett 33 doi:10.1029/2005GL024916

Kug J-S, Sooraj KP, Li T, Jin F-F, Kang I-S (2010) Precursors of the El Niño/La Niña onset and their inter-relationship. J Geophys Res, 115, D05106, doi:10.1029/2009JD012861.

Kucharski F, Bracco A, Yoo JH, Molteni F (2007) Low-frequency variability of the Indian monsoon-ENSO relationship and the tropical Atlantic: the "weakening" of the 1980s and 1990s. J Clim 20:4255-4266. doi:10.1175/JCLI4254.1

Kucharski F, Bracco A, Yoo JH, Molteni F (2008) Atlantic forced component of the Indian monsoon interannual variability. Geophys Res Lett 35:L04706. doi:10.1029/2007GL033037

Kucharski F, Kang I-S, Farneti R, Feudale L (2011) Tropical Pacific response to 20th century Atlantic warming. Geophys Res Lett 38:L03702. doi:10.1029/2010GL046248

Kurcharski F, Syed FS, Burhan A, Farah I, Gohar A (2015) Tropical Atlantic influence on Pacific variability and mean state in the twentieth century in observations and CMIP5. Clim Dyn 44:881-896. doi:10.1007/s00382-014-2228-z

Li G, Xie S-P, Du Y (2015) Monsoon-induced biases of climate models over the Tropical Indian Ocean. J Clim 28:3058-3072. doi: 10.1175/JCLI-D-14-00740.1

Liu L, Xie S-P, Zheng X-T, Li T, Du Y, Huang G, Yu W-D (2014) Indian Ocean variability 
1127

1128

1129

1130

1131

1132

1133

1134

1135

1136

1137

1138

1139

1140

1141

1142

1143

1144

1145

1146

1147

1148

1149

1150

1151

1152

1153

1154

1155

1156

1157

1158

1159

1160

1161

1162

1163

1164

1165

1166

1167

1168

1169

1170

1171

in the CMIP5 multi-model ensemble: The zonal dipole mode. Clim Dyn 43:1715-1730. doi:10.1007/s00382-013-2000-9

Losada T, Rodriguez-Fonseca B, Polo I, Janicot S, Gervois S, Chauvin F, Ruti P (2010) Tropical response to the Atlantic equatorial mode: AGCM multimodel approach. Clim Dyn 5:45-52. doi:10.1007/s00382-009-0624-6

Luo JJ, Masson S, Behera SK, Shingu S, Yamagata T (2005a) Seasonal climate predictability in a coupled OAGCM using a different approach for ensemble forecasts. J Clim 18:44744497. doi:10.1175/JCLI3526.1

Luo JJ, Masson S, Roeckner E, Madec G, Yamagata T (2005b) Reducing climatology bias in an ocean-atmosphere CGCM with improved coupling physics. J Clim 18:2344-2360

Luo JJ, Zhang R, Behera SK, Masumoto Y, Jin F-F, Lukas R, Yamagata T (2010) Interaction between El Niño and extreme Indian Ocean dipole, J Climate 23:726-742.

Madec G (2008) NEMO ocean engine. Note du Pole de modelisation, Institut Pierre-Simon Laplace (IPSL) No 27. ISSN No 1288-1619

Masson S, Terray P, Madec G, Luo J-J, Yamagata T, Takahashi K (2012) Impact of intradaily SST variability on ENSO characteristics in a coupled model. Clim Dyn. doi:10.1007/s00382-011-1247-2

Ohba M, Ueda H (2007) An impact of SST anomalies in the Indian Ocean in acceleration of the El Niño to La Niña transition, J Meteorol Soc Jpn 85:335-348.

Polo I, Martin-Rey M, Rodriguez-Fonseca B, Kucharski F, Mechoso CR (2014) Processes in the Pacific La Niña onset triggered by the Atlantic Niño. Clim Dyn. doi:10.1007/s00382-0142354-7

Prodhomme C, Terray P, Masson S, Izumo T, Tozuka T, Yamagata T (2014) Impacts of Indian Ocean SST biases on the Indian Monsoon: as simulated in a global coupled model. Clim Dyn 42:271-290. doi:10.1007/s00382-013-1671-6

Prodhomme C, Terray P, Masson S, Boschat G, Izumo T (2015) Oceanic factors controlling the Indian Summer Monsoon Onset in a coupled model. Clim Dyn 44:977-1002. doi:10.1007/s00382-014-2200-y

Rayner NA, Parker DE, Horton EB, Folland CK, Alexander LV, Rowell DP, Kent EC, Kaplan A (2003) Global analyses of sea surface temperature, sea ice, and night marine air temperature since the late nineteenth century. J Geophys Res 108. doi:10.1029/2002JD002670

Reynolds RW, Smith TM, Liu C, Chelton DB, Casey KS, Schlax MG (2007) Daily high- 
resolution-blended analyses for sea surface temperature. J Clim 20:5473-5496. doi:10.1175/2007JCLI1824.1

Richter I, Xie S-P, Behera SK, Doi T, Masumoto Y (2014) Equatorial Atlantic variability and its relation to mean state biases in CMIP5. Clim Dyn 42:171-188. doi:10.1007/s00382-012$1624-5$

Rodriguez-Fonseca B, Polo I, Garcia-Serrano J, Losada T, Mohino E, Mechoso CR, Kucharski F (2009) Are Atlantic Ninos enhancing Pacific ENSO events in recent decades? Geophys Res Lett 36:L20705. doi:10.1029/2009GL040048

Roxy M, Rikita K, Terray P, Masson S (2014) The curious case of Indian Ocean warming. J

Roeckner E, Baüml G, Bonaventura L, Brokopf R, Esch M, Girogetta M, Hagemann S, Kirchner I, Kornblueh L, Manzini E, Rhodin A, Schlese U, Schulzweida U, Tompkins A (2003) The atmospheric general circulation model ECHAM 5, Part I, MPI Report, vol 349. Max-Planck-Institut für Meteorologie, Hamburg, pp 137

Santoso A, England MH, Cai W (2012) Impact of Indo-Pacific feedback interactions on ENSO dynamics diagnosed using ensemble climate simulations. J. Climate, 25, 7743-7763.

Terray P (2011) Southern Hemisphere extra-tropical forcing: a new paradigm for El NiñoSouthern Oscillation. Clim Dyn 36:2171-2199. doi:10.1007/s00382-010-0825-z

Terray P, Kamala K, Masson S, Madec G, Sahai A K, Luo J-J, Yamagata T (2012) The role of the intra-daily SST variability in the Indian monsoon variability and monsoon-ENSO-IOD relationships in a global coupled model. Clim Dyn 39:729-754. doi:10.1007/s00382-011$1240-9$

Timmermann R, Goosse H, Madec G, Fichefet T, Ethe C, Duliere V (2005) On the representation of high latitude processes in the ORCA-LIM global coupled sea ice-ocean model. Ocean Model 8:175-201

Tollefson J (2014) El Niño tests forecasters. Nature 508:20-21 (03 April 2014). doi:10.1038/508020a.

Valcke (2006) OASIS3 user guide (prism_2-5). CERFACS technical report TR/CMGC/06/73, PRISM report no. 3, Toulouse, pp 64

Vimont DJ, Wallace JM, Battisti DS (2003) The seasonal footprinting mechanism in the Pacific: Implications for ENSO, J. Climate 16:2668-2675

Wang S-Y, L'Heureux M, Chia H-H (2012) ENSO prediction one year in advance using western North Pacific sea surface temperatures. Geophys Res Lett 39:L05702. 
1219 Weisberg RH, Wang C (1997) A western pacific oscillator paradigm for the el niño-southern oscillation. Geophys Res Lett 24:779-782

Wyrtki K (1975) El Niño-the dynamic response of the equatorial Pacific Oceanto atmospheric forcing. J Phys Oceanogr 5:572-584

Wu R, Kirtman BP (2004) Understanding the impacts of the Indian Ocean on ENSO variability in a coupled GCM. J. Climate 17:4019-4031

Yeh S-W, Wu R, Kirtman B (2007) Impact of the Indian Ocean on ENSO variability in a hybrid coupled model. Quart J Roy Meteor Soc 133:445-457

Yu J-Y (2005) Enhancement of ENSO's persistence barrier by biennial variability in a coupled atmosphere-ocean general circulation model. Geophys Res Lett 32:L13707. doi: 10.1029/2005GL023406

Yu J-Y, Mechoso CR, McWilliams JC, Arakawa A (2002) Impacts of the Indian Ocean on the ENSO cycle. Geophys Res Lett 29:1204. doi:10.1029/2001GL014098

1241 Zhang Y, Norris JR, Wallace JM (1998) Seasonality of large scale atmosphere-ocean 
1246 Figure 1: a) SST mean state in $\operatorname{REF}\left({ }^{\circ} \mathrm{C}\right)$ from 190-year annual mean (years 11-210 of REF), 1247 b) SST means difference $\left({ }^{\circ} \mathrm{C}\right.$ ) between REF (years 11-210) and HadISST1.1 dataset (years 1248 1979-2012), c) SST standard deviation in REF $\left({ }^{\circ} \mathrm{C}\right)$ and d) SST standard deviation difference $\left({ }^{\circ} \mathrm{C}\right.$ ) between REF (years 11-210) and HadISST1.1 dataset (years 1979-2012).

Figure 2: a) Monthly standard deviations of the Niño-34 SST time series from HadISST1.1 dataset (for the 1950-2012 and 1979-2012 periods) and the five experiments; b) Power spectra of Niño-34 SST anomalies for HadISST1.1 dataset (Rayner et al. 2003) in black, REF in red, FTIC and FTIC-obs in green, FTAC and FTAC-obs in blue. The bottom axis is the period (unit: year), the left axis is variance (unit: ${ }^{\circ} \mathrm{C}^{2}$ ) and both axes are in logarithm scale. Dashed black curves show the point-wise 99\% confidence limits for the Niño-34 SST spectrum estimated from the observations. The observed Niño-34 SST spectrum is estimated from the 1901-2012 period.

Figure 3: Lagged correlations between bi-monthly averaged SSTs and the December-January Niño-3.4 SST for a) REF and b) HadISST1.1. The correlations are calculated beginning in February-March of year0, prior to the El Niño onset, and ending in December-January at the peak season of El Niño events. For observations, the correlations are computed from the 1950-2012 period. Correlations that are above the 90\% significance confidence level according to a phase-scramble bootstrap test (Ebisuzaki 1997) are contoured.

Figure 4: Maps of the difference of annual mean SST climatologies between a) REF and of the difference of SST standard deviation between e) REF and FTIC, f) REF and FTIC-obs, g) $\mathrm{REF}$ and FTAC and $\mathbf{h}) \mathrm{REF}$ and FTAC-obs. Units $={ }^{\circ} \mathrm{C}$.

Figure 5: Logarithm of the ratio of the power spectra of the Niño-3.4 SST for a) REF/FTIC, b) REF/FTIC-obs, c) REF/FTAC and d) REF/FTAC-obs on a logarithmic scale and pointwise $90 \%$ confidence intervals (blue lines) for the logarithms of the spectral ratios for a postulated common spectrum in the two experiments.

Figure 6: Lead-lag correlations between bi-monthly averaged depth of $20^{\circ} \mathrm{C}$ isotherm anomalies (20d) and the December-January (year0) Niño-3.4 SST for REF (left column), FTIC (middle column) and FTAC (right column). The correlations are shown only for February-March of year-1, December-January of year-1, December-January of year0 (during the El Niño peak) and October-November of year+1. Correlations that are above the 90\% significance confidence level according to a phase-scramble bootstrap test (Ebisuzaki 1997) are underlined. 
Figure 7: a) and b) Maps of the spatial patterns of the leading SST-USTR MCA mode for REF. a) SST homogeneous vectors in ${ }^{\circ} \mathrm{C}, \mathrm{CI}=0.1^{\circ} \mathrm{C}$. b) USTR heterogeneous vectors in $\mathrm{N} / \mathrm{m}^{2}, \mathrm{CI}=0.2 \mathrm{~N} / \mathrm{m}^{2}$. The maps were obtained by regressing the SST and USTR fields upon the normalized EC time series of SST. The SST and USTR fields are, respectively, homogenous and heterogeneous covariance patterns following the terminology of Bretherton et al. (1992). Summary statistics for this mode are given in Table 3. c) and d) same as a) and b), but for the leading USTR-20d MCA mode for REF. Units for USTR and 20d are in N/m² and $\mathrm{m}$, respectively. Summary statistics for this mode are given in Table 4.

Figure 8: a) Lead regressions between bi-monthly averaged $850 \mathrm{hPa}$ wind and SLP anomalies and b) $10-\mathrm{m}$ wind and precipitation anomalies during El Niño onset (e.g. from December-January to April-May of year0) and the December-January (at the end of year0) Niño-3.4 SST for REF. Regressions that are above the 90\% significance confidence level according to a phase-scramble bootstrap test (Ebisuzaki 1997) are underlined and only the $850 \mathrm{hPa}$ wind anomalies above the $90 \%$ significance confidence level are shown.

Figure 9: Lagged correlations between bi-monthly averaged SSTs during year-1 and the December-January (year0) Niño-3.4 SST for a) FTIC and b) FTAC. The correlations are calculated beginning in February-March of year-1, prior to the El Niño onset, and ending in February-March of year0. Correlations that are above the $90 \%$ significance confidence level according to a phase-scramble bootstrap test (Ebisuzaki 1997) are underlined.

Figure 10: Lagged regressions between bi-monthly averaged $850 \mathrm{hPa}$ wind and SLP anomalies during year-1 and the December-January (year0) Niño-3.4 SST for FTIC. Regressions that are above the $90 \%$ significance confidence level according to a phasescramble bootstrap test (Ebisuzaki 1997) are underlined and only the $850 \mathrm{hPa}$ wind anomalies above the $90 \%$ significance confidence level are shown.

Figure 11: Same as Figure 10, but for the FTAC experiment.

Figure 12: Lead regressions between bi-monthly averaged SSTs during year+1 and the December-January (year0) Niño-3.4 SST for a) REF, b) FTIC and c) FTAC. The regressions are calculated beginning in April-May of year+1, after the El Niño peak phase, and ending in October-November of year+1. Regressions that are above the $90 \%$ significance confidence level according to a phase-scramble bootstrap test (Ebisuzaki 1997) are underlined.

Figure 13: Same as Figure 12, but for bi-monthly 10m zonal wind anomalies.

Figure 14: Same as Figure 12, but for $200 \mathrm{hPa}$ wind and velocity potential anomalies. 
1327 Table 1: Summary of the numerical experiments with their main characteristics, including 1328 length, nudging domain and SST climatology used for the nudging in the Indian or Atlantic oceans decoupled experiments.

Table 2: Standard-deviations (in $\left.{ }^{\circ} \mathrm{C}\right)$ of Niño-3.4 $\left(5^{\circ} \mathrm{S}-5^{\circ} \mathrm{N}, 170-120^{\circ} \mathrm{W}\right)$, ATL3 $\left(5^{\circ} \mathrm{S}-5^{\circ} \mathrm{N}\right.$, $\left.340-360^{\circ} \mathrm{E}\right), \operatorname{IOB}\left(20^{\circ} \mathrm{S}-20^{\circ} \mathrm{N}, 40-110^{\circ} \mathrm{E}\right)$, and IOD SST indices in observations and REF. The IOD index is computed as the differences between the SST anomalies in a western $\left(10^{\circ} \mathrm{S}-10^{\circ} \mathrm{N}, 60-80^{\circ} \mathrm{E}\right)$ and eastern $\left(0-10^{\circ} \mathrm{S}, 90-110^{\circ} \mathrm{E}\right)$ box in the tropical Indian Ocean. The different indices are computed as seasonal averages as defined in the first row of the Table. These seasons correspond to the peak season of the indices in the observations. The statistics for the observations are derived from the HadISST1.1 dataset. The statistical significance of the differences between the observed and simulated standard-deviations has been assessed with the help of a Fisher test. The simulated standard-deviations significant at the $95 \%$ confidence level are in bold.

Table 3: Summary statistics for the SST-USTR MCA leading modes estimated from the

1343 REF, FTIC, FTIC-obs, FTAC and FTAC-obs experiments, including the SCFs and NCs for 1344 the leading modes in the various MCA expansions and the correlation $(r)$ between the EC time series of the left and right fields. SCF stands for Square Covariance Fraction and NC for Normalized root-mean-square Covariance, as given in the text. As discussed by Zhang et al. (1998), the NC and $r$ coefficients are particularly useful in comparing the strength of the coupling between the left and right fields in modes obtained from different MCAs. SSTvar and USTRvar are, respectively, SST and USTR variances accounted for by the leading mode of each MCA analysis (e.g. this is the variance of the field explained by the related Expansion Coefficient time series by linear regression).

1352 Table 4: Same as Table 3, but for the USTR-20d MCA leading modes from the REF, FTIC, FTIC-obs, FTAC and FTAC-obs experiments. 
Figure 1
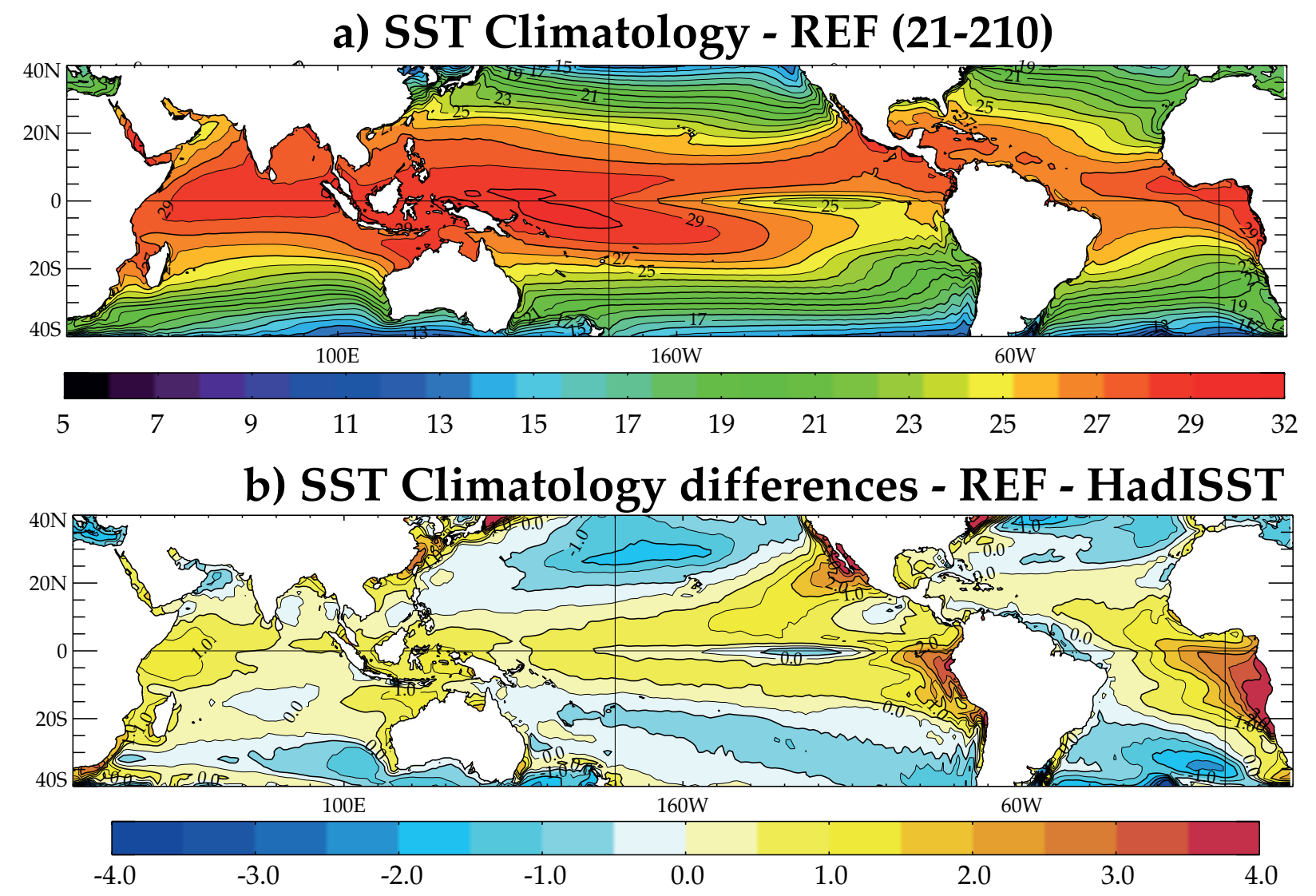

c) SST Standard-Deviation - REF (21-210)
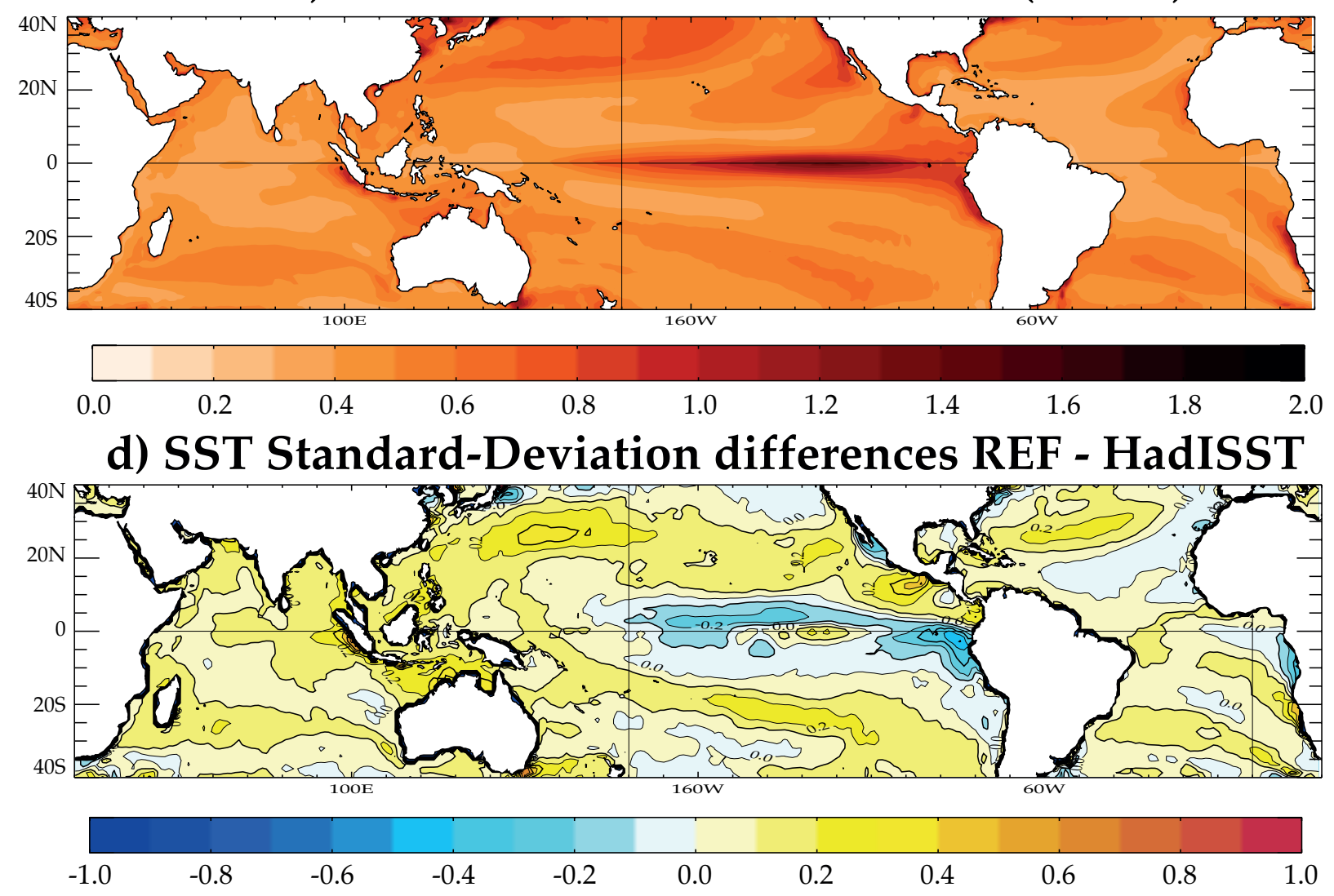

Figure 1: a) SST mean state in REF ( ${ }^{\circ} \mathrm{C}$ ) from 190-year annual mean (years 11-210 of REF), b) SST means difference $\left({ }^{\circ} \mathrm{C}\right.$ ) between REF (years 11-210) and HadISST1.1 dataset (years 1979-2012), c) SST standard deviation in REF $\left({ }^{\circ} \mathrm{C}\right)$ and d) SST standard deviation difference $\left({ }^{\circ} \mathrm{C}\right.$ ) between REF (years 11-210) and HadISST1.1 dataset (years 1979-2012). 
a) Nino34 SSTs monthly STDs
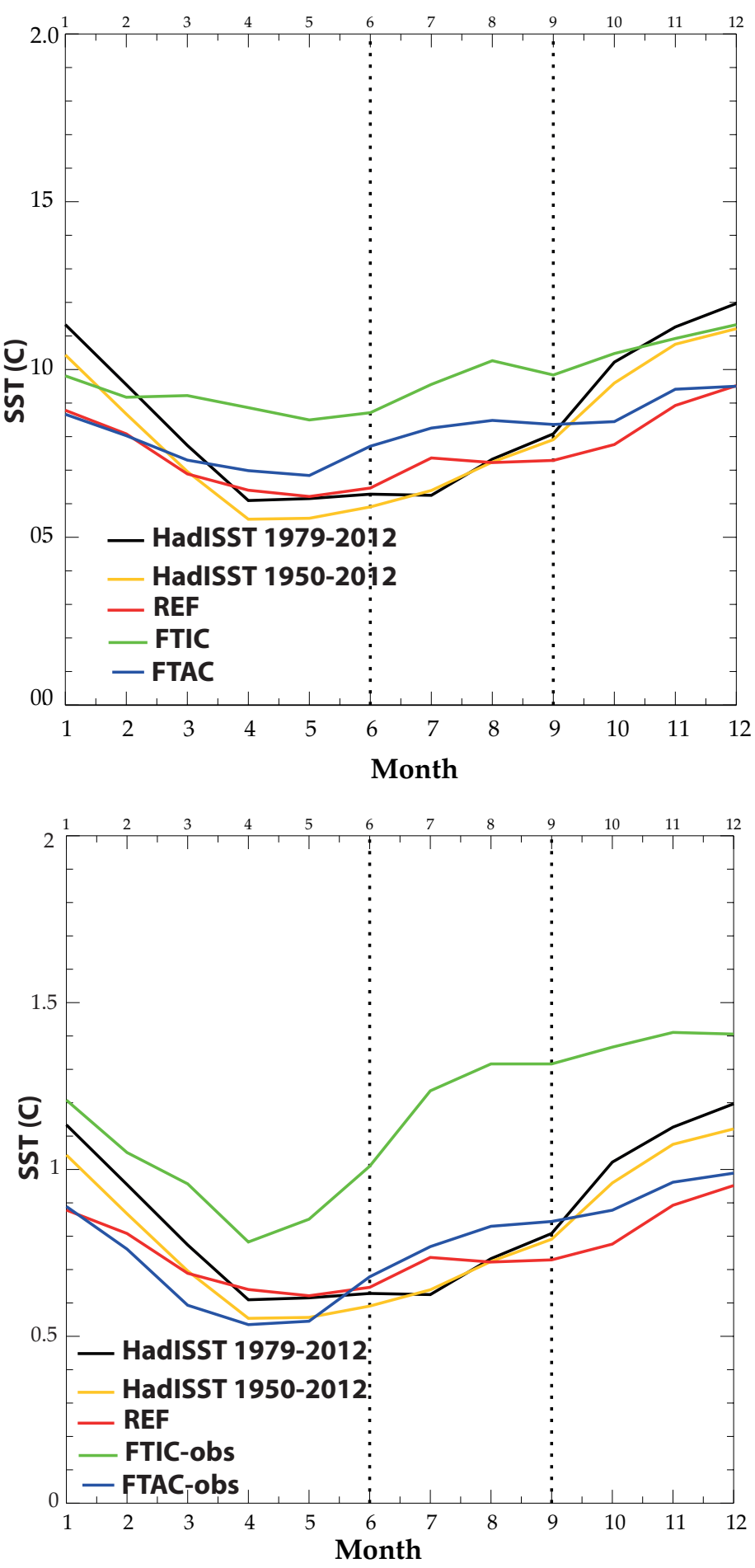

b) Nino34 SSTs spectrum
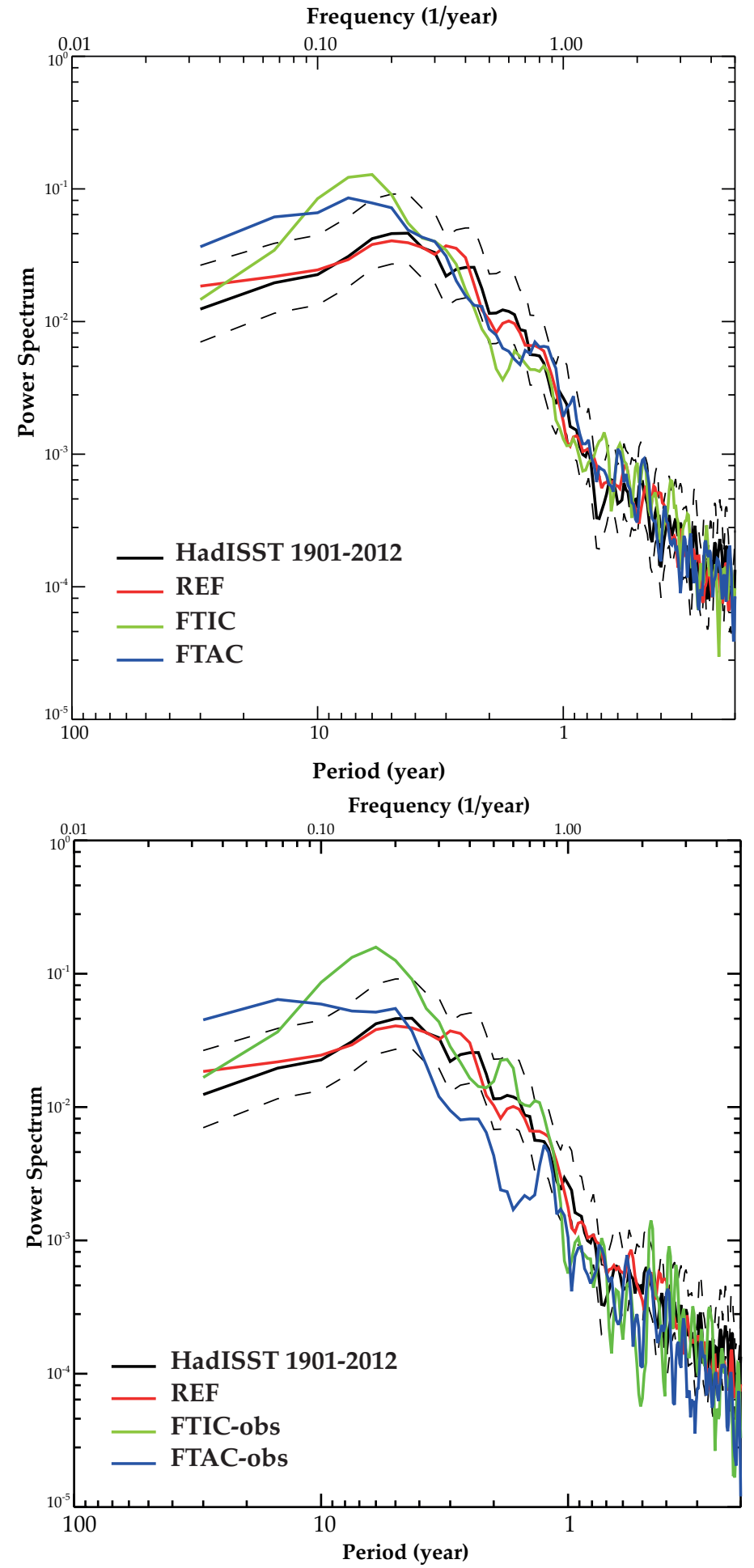

Figure 2: a) Monthly standard deviations of the Niño-34 SST time series from HadISST1.1 dataset (for the 1950-2012 and 1979-2012 periods) and the five experiments; b) Power spectra of Niño-34 SST anomalies for HadISST1.1 dataset (Rayner et al. 2003) in black, REF in red, FTIC and FTIC-obs in green, FTAC and FTAC-obs in blue. The bottom axis is the period (unit: year), the left axis is variance (unit: ${ }^{\circ} \mathrm{C} 2$ ) and both axes are in logarithm scale. Dashed black curves show the point-wise $99 \%$ confidence limits for the Niño-34 SST spectrum estimated from the observations. The observed Niño-34 SST spectrum is estimated from the 1901-2012 period. 


\section{Correlations Nino34 SST (12-1) SST - Year 0}

\section{a) REF (21-210)}
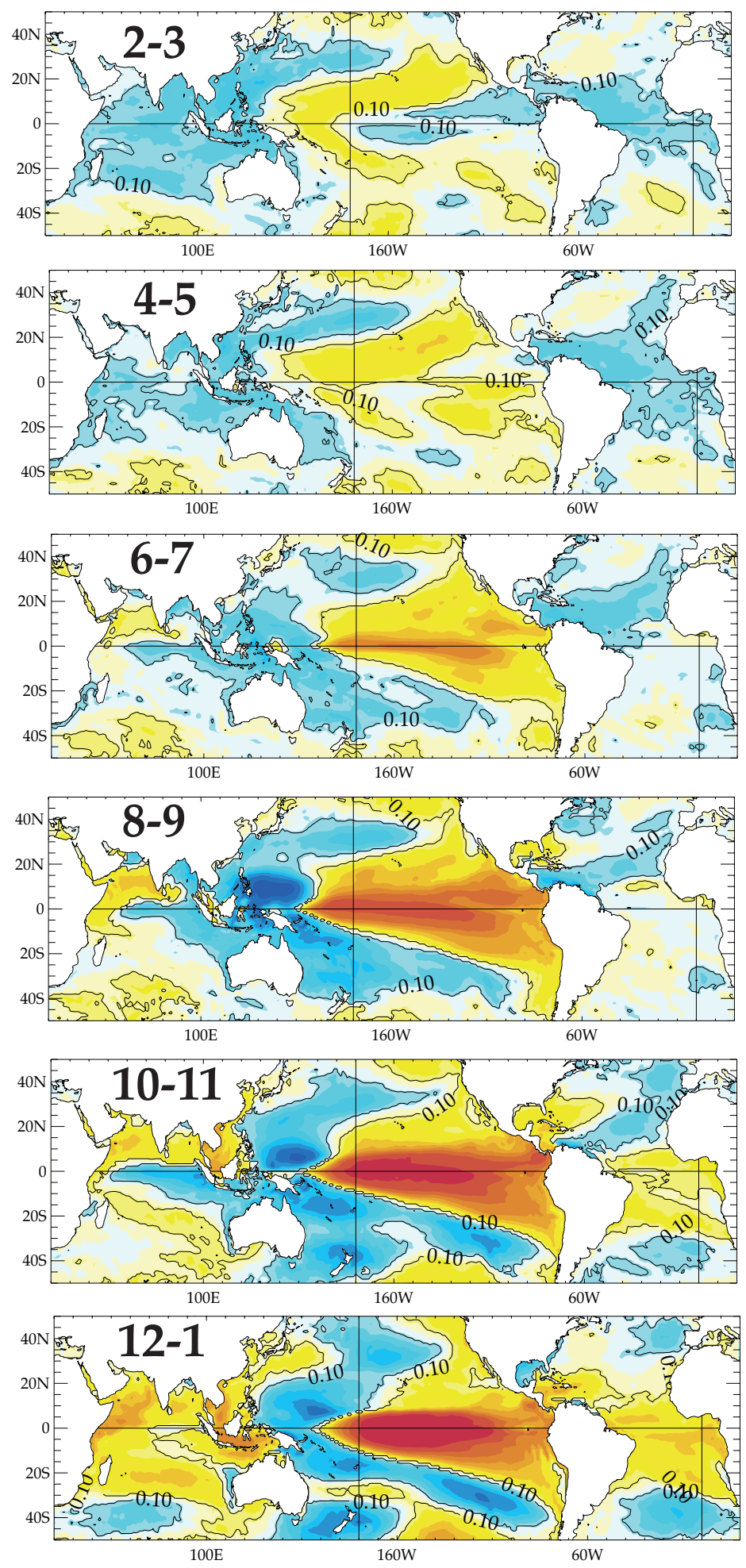

b) HadISST (1950-2012)
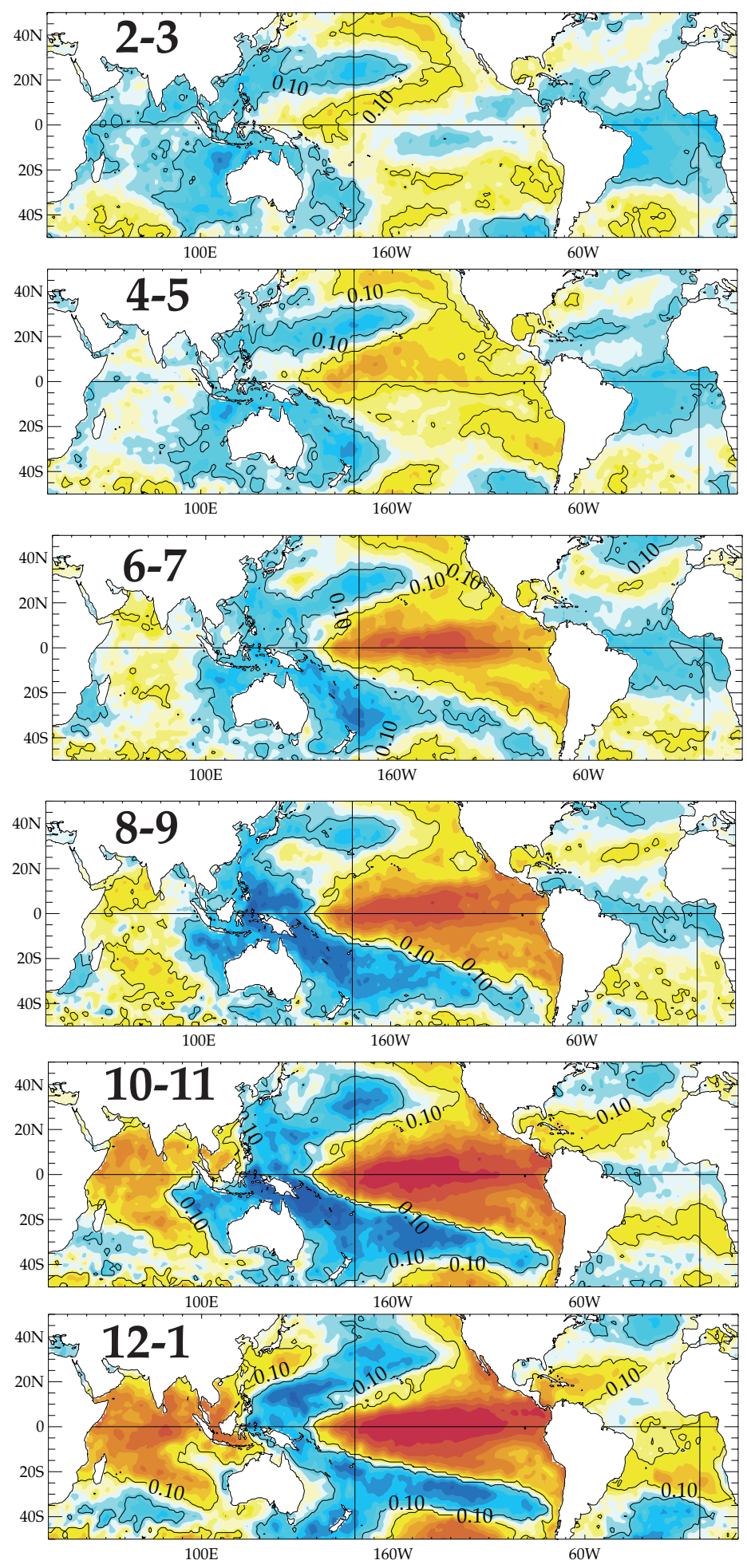

\section{$\begin{array}{lllllllllll}-1.0 & -0.8 & -0.6 & -0.4 & -0.2 & 0.0 & 0.2 & 0.4 & 0.6 & 0.8 & 1.0\end{array}$ \\ CORRELATION}

Figure 3: Lagged correlations between bi-monthly averaged SSTs and the December-January Niño-3.4 SST for a) REF and b) HadISST1.1. The correlations are calculated beginning in FebruaryMarch of year0, prior to the El Niño onset, and ending in December-January at the peak season of El Niño events. For observations, the correlations are computed from the 1950-2012 period. Correlations that are above the $90 \%$ significance confidence level according to a phase-scramble bootstrap test (Ebisuzaki 1997) are underlined. 


\section{Figure 4}
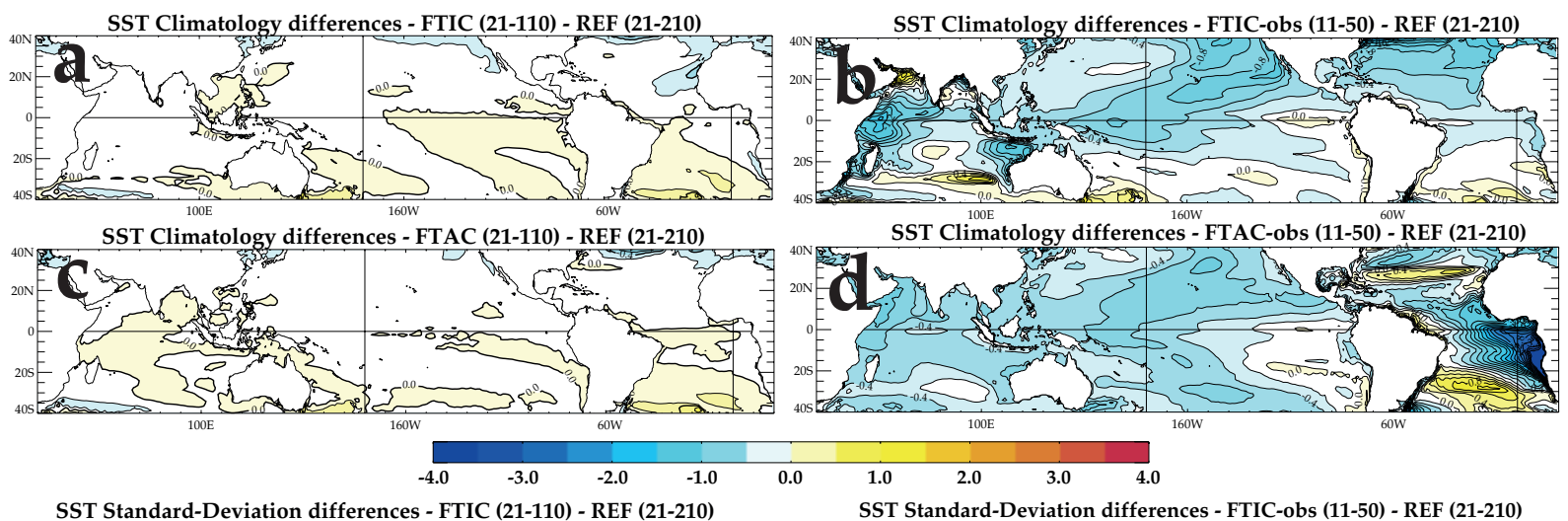

SST Standard-Deviation differences - FTIC (21-110) - REF (21-210) SST Standard-Deviation differences - FTIC-obs (11-50) - REF (21-210)

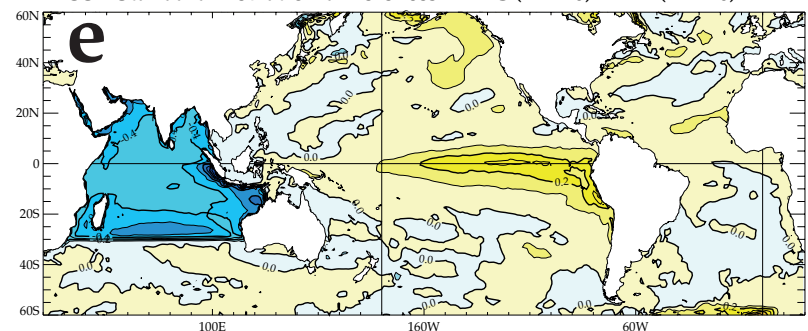

SST Standard-Deviation differences - FTAC (21-110) - REF (21:210)

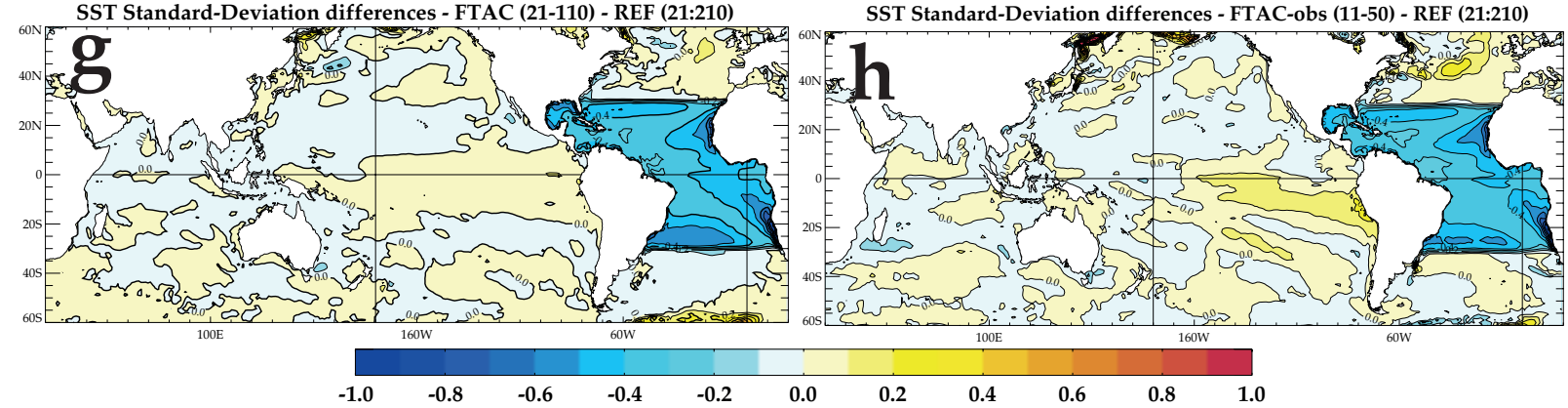

Figure 4: Maps of the difference of annual mean SST climatologies between a) REF and FTIC, b) REF and FTIC-obs, c) REF and FTAC and d) REF and FTAC-obs. Units $={ }^{\circ} \mathrm{C}$. Maps of the difference of SST standard deviation between e) REF and FTIC, f) REF and FTIC-obs, g) REF and FTAC and h) REF and FTAC-obs. Units $={ }^{\circ} \mathrm{C}$. 


\section{Figure 6 Correlations Nino34 SST (12-1) 20d}

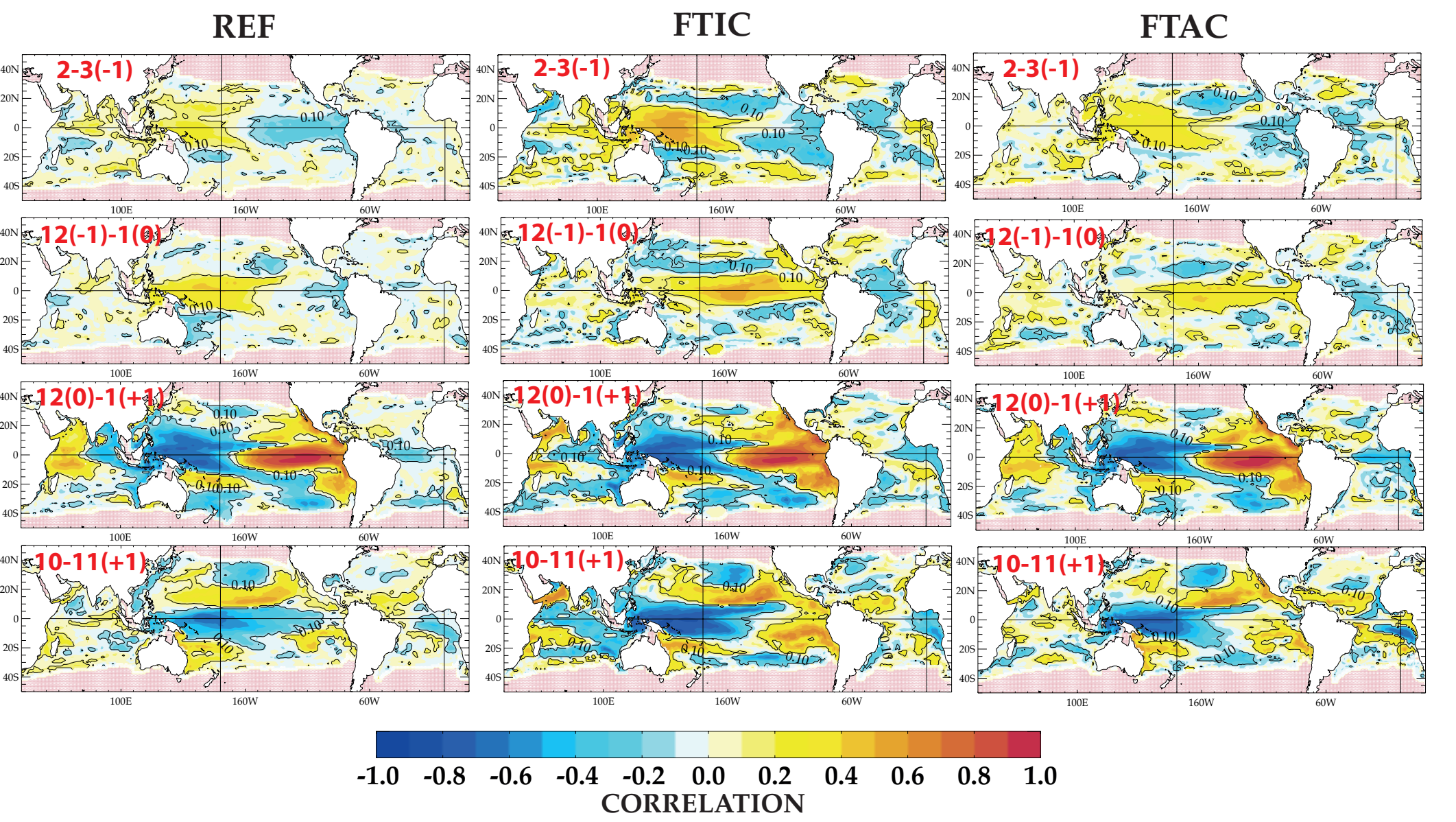

Figure 6: Lead-lag correlations between bi-monthly averaged depth of $20^{\circ} \mathrm{C}$ isotherm anomalies (20d) and the December-January (year0) Niño-3.4 SST for REF (left column), FTIC (middle column) and FTAC (right column). The correlations are shown only for February-March of year-1, December-January of year-1, December-January of year0 (during the El Niño peak) and October-November of year+1. Correlations that are above the $90 \%$ significance confidence level according to a phase-scramble bootstrap test (Ebisuzaki 1997) are underlined. 
a) SST Homogeneous Vector - MCA Mode 1 - REF

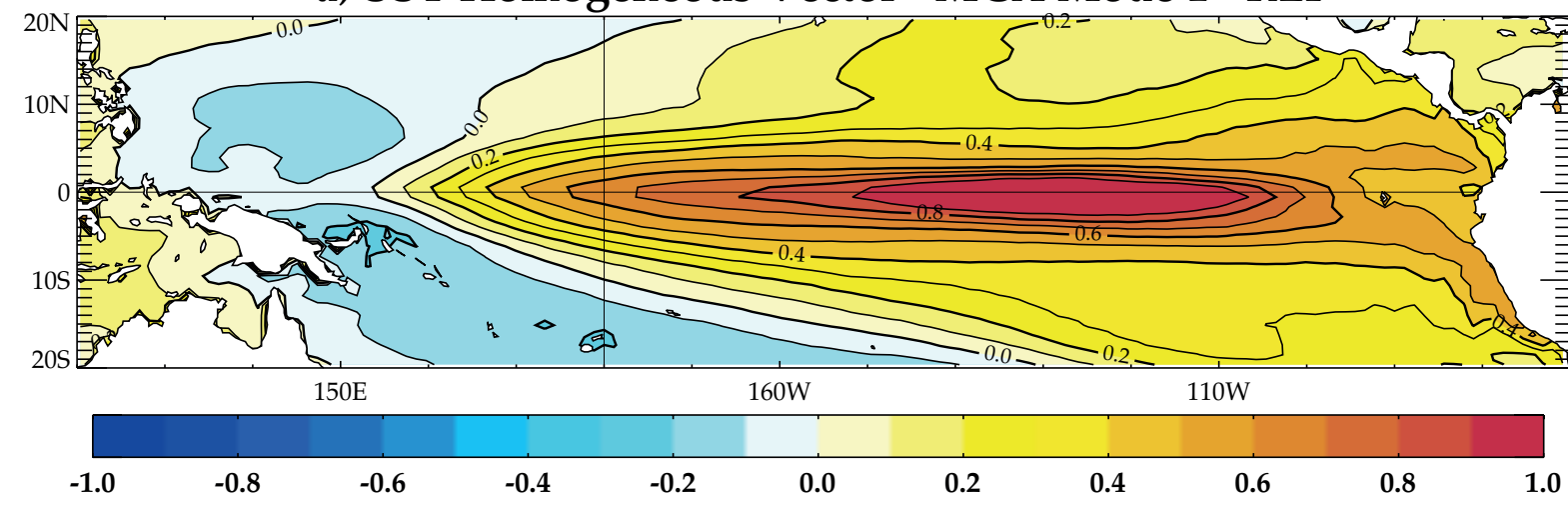

b) USTR Heterogeneous Vector - MCA Mode 1 - REF
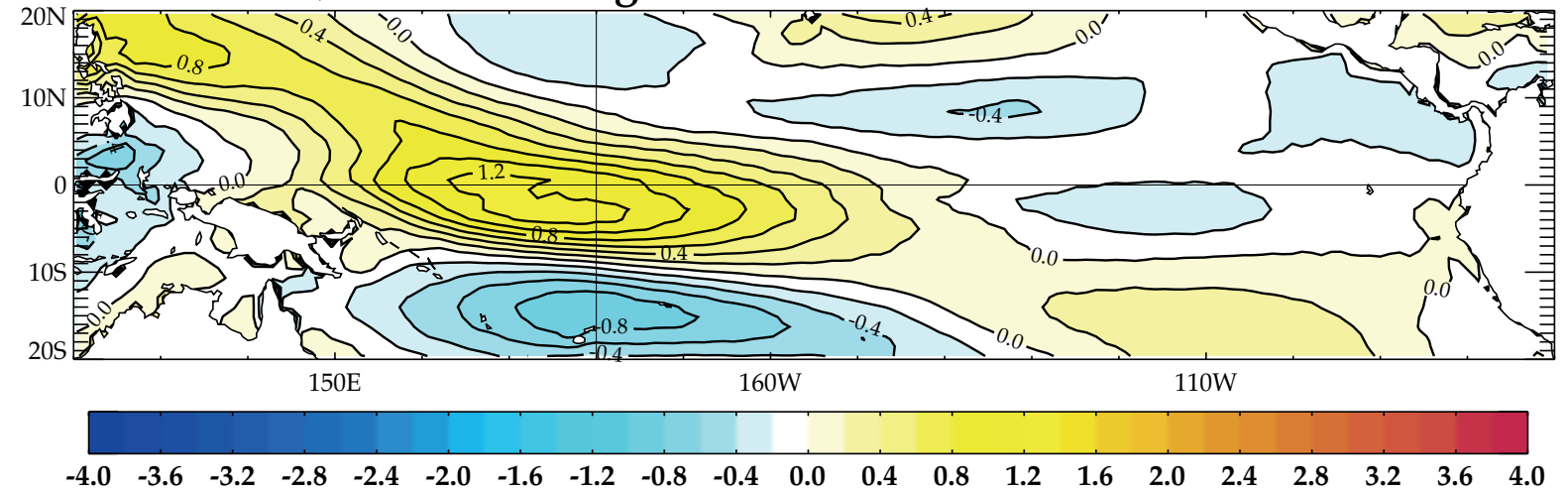

c) USTR Homogeneous Vector - MCA Mode 1 - REF
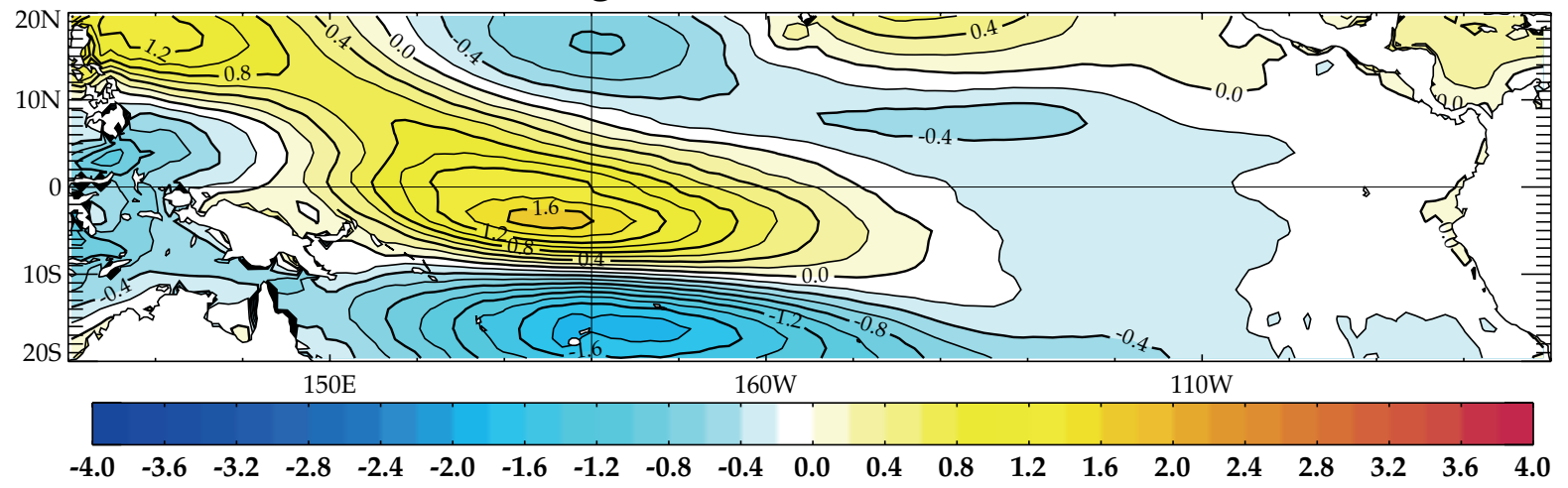

d) 20d Heterogeneous Vector - MCA Mode 1 - REF

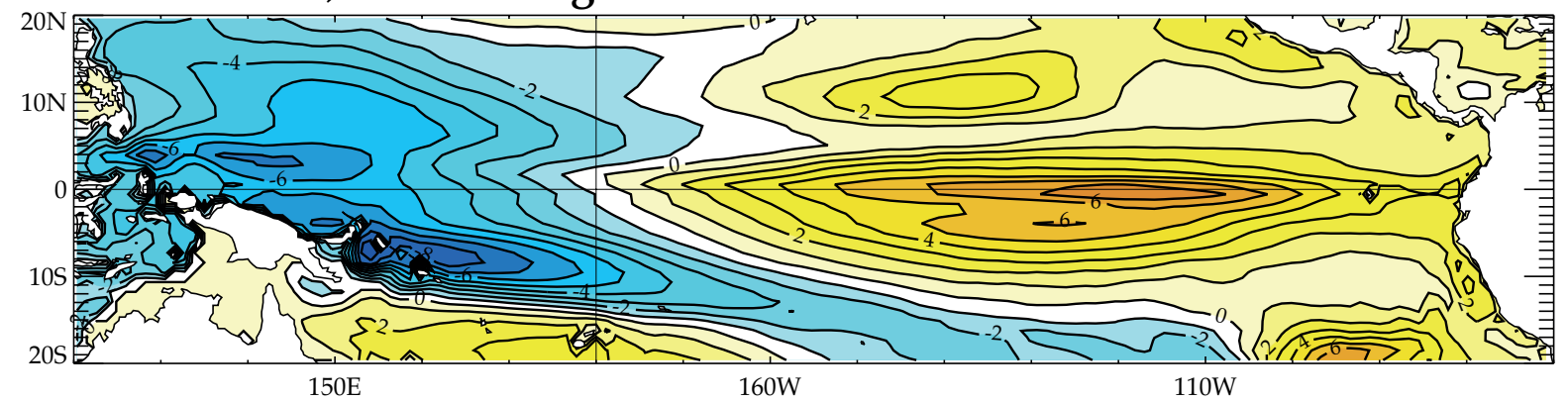

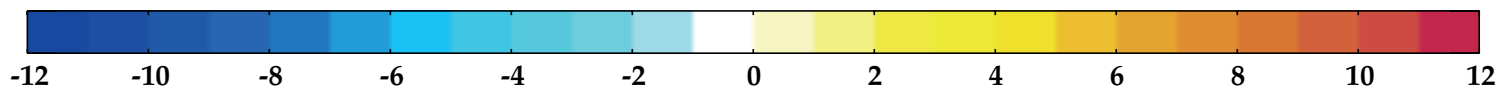

Figure 7: a) and b) Maps of the spatial patterns of the leading SST-USTR MCA mode for REF. a) SST homogeneous vectors in ${ }^{\circ} \mathrm{C}, \mathrm{Cl}=0.1^{\circ} \mathrm{C}$. b) USTR heterogeneous vectors in $\mathrm{N} / \mathrm{m} 2, \mathrm{Cl}=0.2 \mathrm{~N} / \mathrm{m} 2$. The maps were obtained by regressing the SST and USTR fields upon the normalized EC time series of SST. The SST and USTR fields are, respectively, homogenous and heterogeneous covariance patterns following the terminology of Bretherton et al. (1992). Summary statistics for this mode are given in Table 2. c) and d) same as a) and b), but for the leading USTR-20d MCA mode for REF. Units for USTR and $20 \mathrm{~d}$ are in N/m2 and $\mathrm{m}$, respectively. Summary statistics for this mode are given in Table 3. 
Figure 8

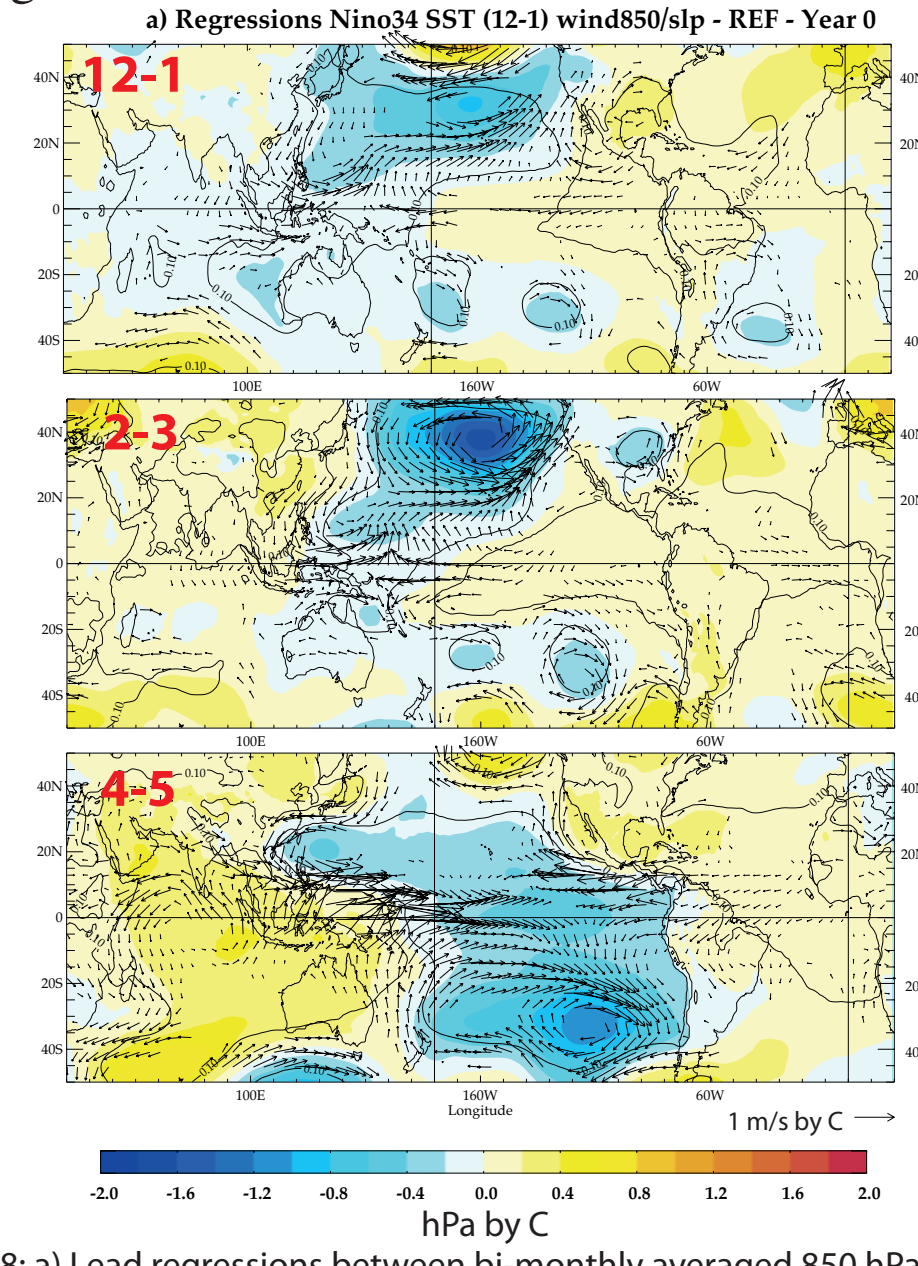

b) Regressions Nino34 SST (12-1) wind10/precip - REF - Year 0
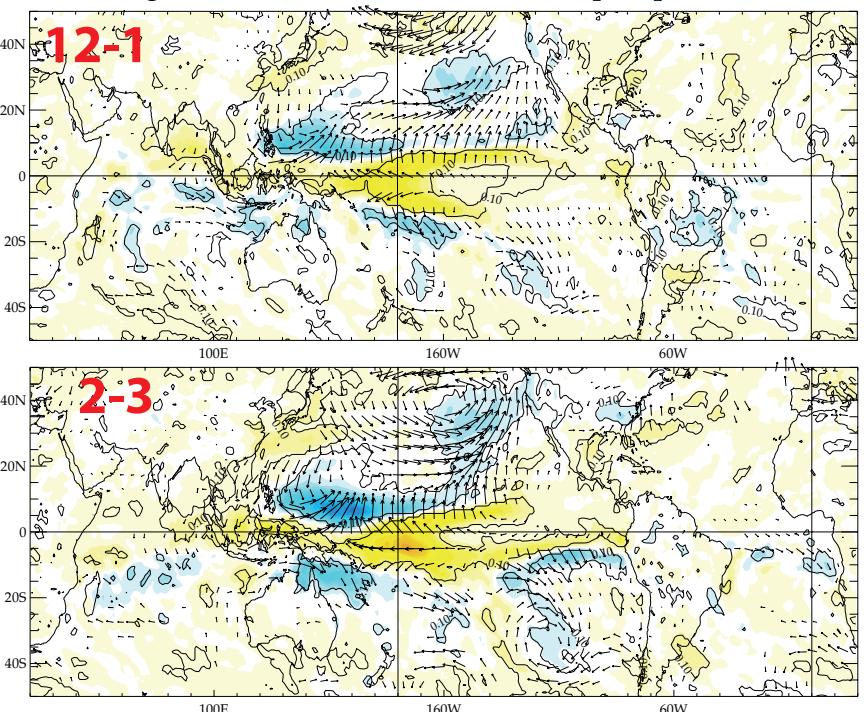

Figure 8: a) Lead regressions between bi-monthly averaged $850 \mathrm{hPa}$ wind and SLP anomalies and b) 10-m wind and precipitation anomalies during El Niño onset (e.g. from December-January to April-May of year0) and the December-January (at the end of year0) Niño-3.4 SST for REF. Regressions that are above the $90 \%$ significance confidence level according to a phase-scramble bootstrap test (Ebisuzaki 1997) are underlined and only the $850 \mathrm{hPa}$ wind anomalies above the $90 \%$ significance confidence level are shown. 


\section{a) FTIC : YEAR -1}

b) FTAC : YEAR -1
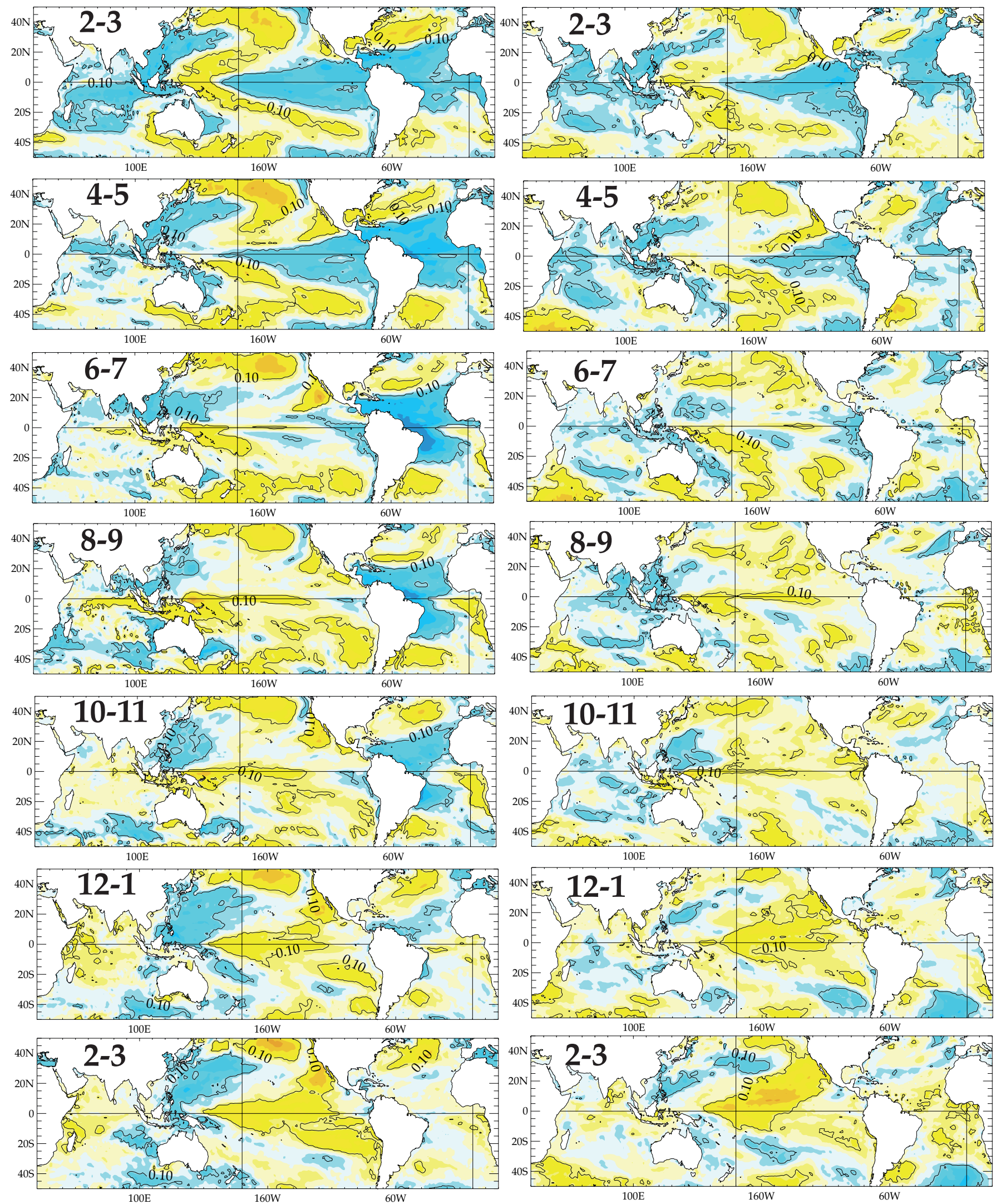

\section{$\begin{array}{lllllllllll}-1.0 & -0.8 & -0.6 & -0.4 & -0.2 & 0.0 & 0.2 & 0.4 & 0.6 & 0.8 & 1.0\end{array}$}

Figure 9: Lagged correlations between bi-monthly averaged SSTs during year-1 and the December-January (year0) Niño-3.4 SST for a) FTIC and b) FTAC. The correlations are calculated beginning in February-March of year-1, prior to the El Niño onset, and ending in February-March of year0. Correlations that are above the $90 \%$ significance confidence level according to a phase-scramble bootstrap test (Ebisuzaki 1997) are underlined. 


\section{figure 10 Regressions Nino34 SST (12-1) wind850/slp - FTIC - Year -1}
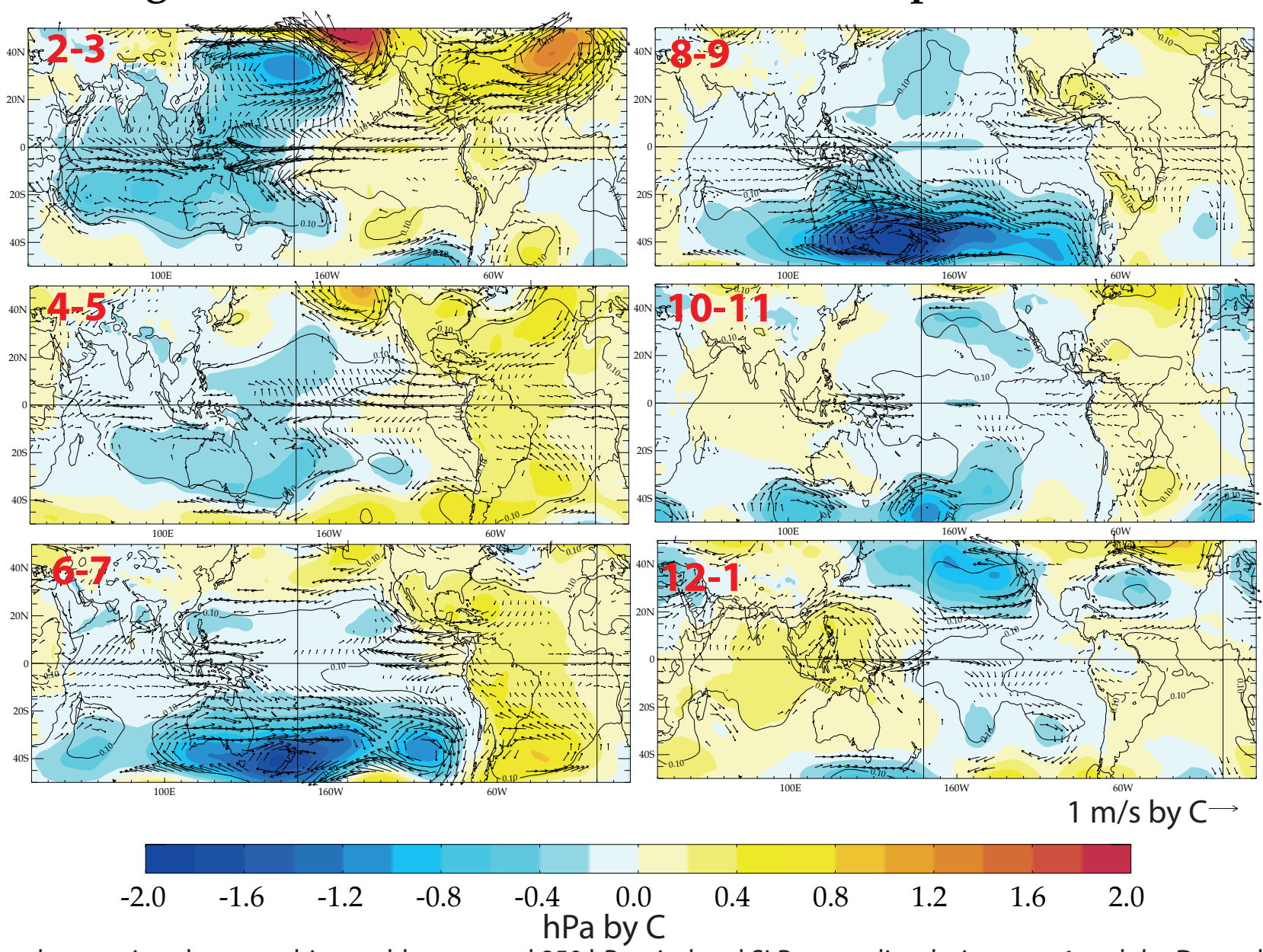

Figure 10: Lagged regressions between bi-monthly averaged $850 \mathrm{hPa}$ wind and SLP anomalies during year-1 and the December-January (year0) Niño-3.4 SST for FTIC. Regressions that are above the $90 \%$ significance confidence level according to a phase-scramble bootstrap test (Ebisuzaki 1997) are underlined and only the $850 \mathrm{hPa}$ wind anomalies above the $90 \%$ significance confidence level are shown. 


\section{figure 11 Regressions Nino34 SST (12-1) wind850/slp - FTAC - Year -1}
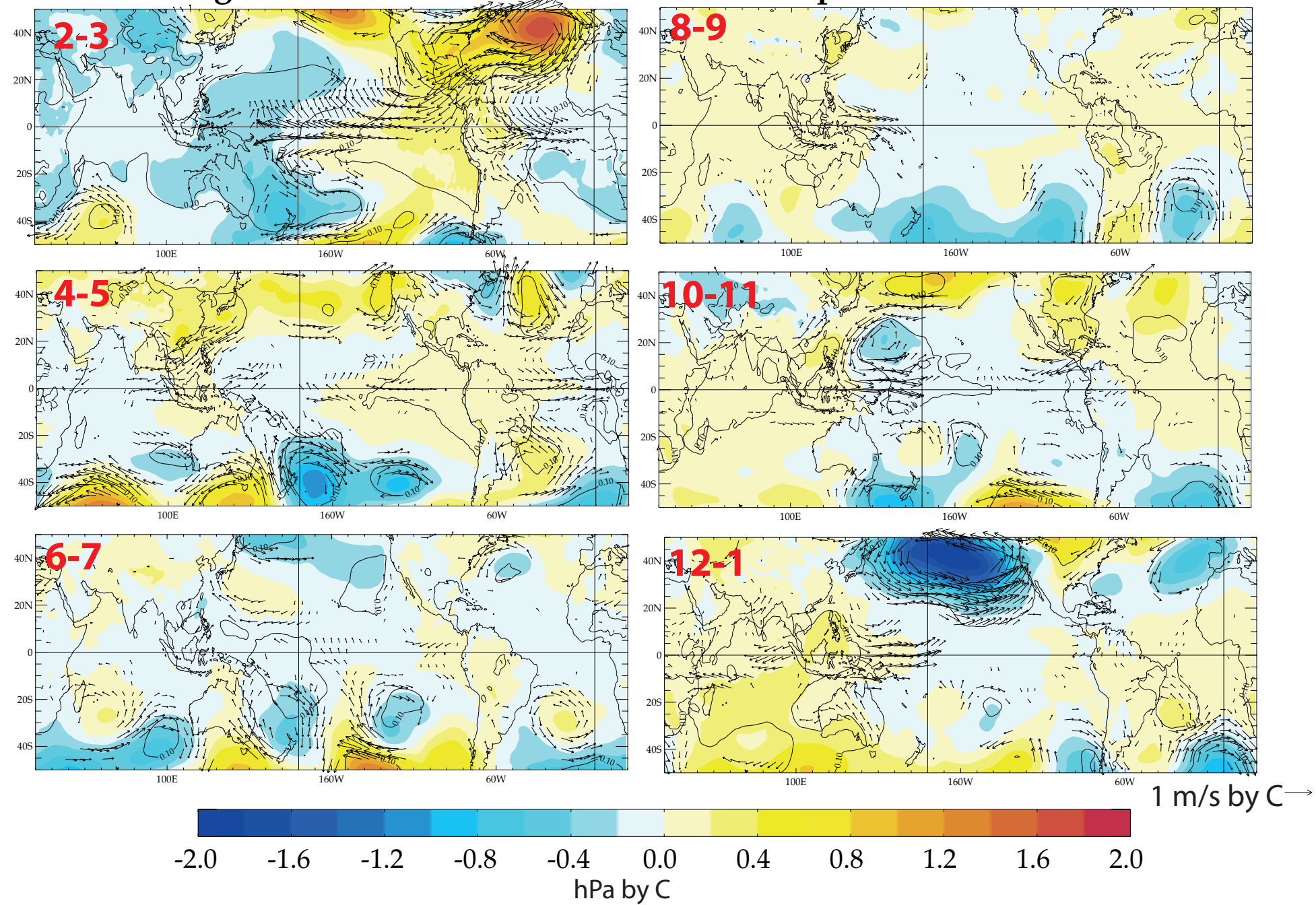

Figure 11: Same as Figure 10, but for the FTAC experiment. 
figure 12 Regressions Nino34 SST (12-1) SST - Year +1 REF FTIC

FTAC
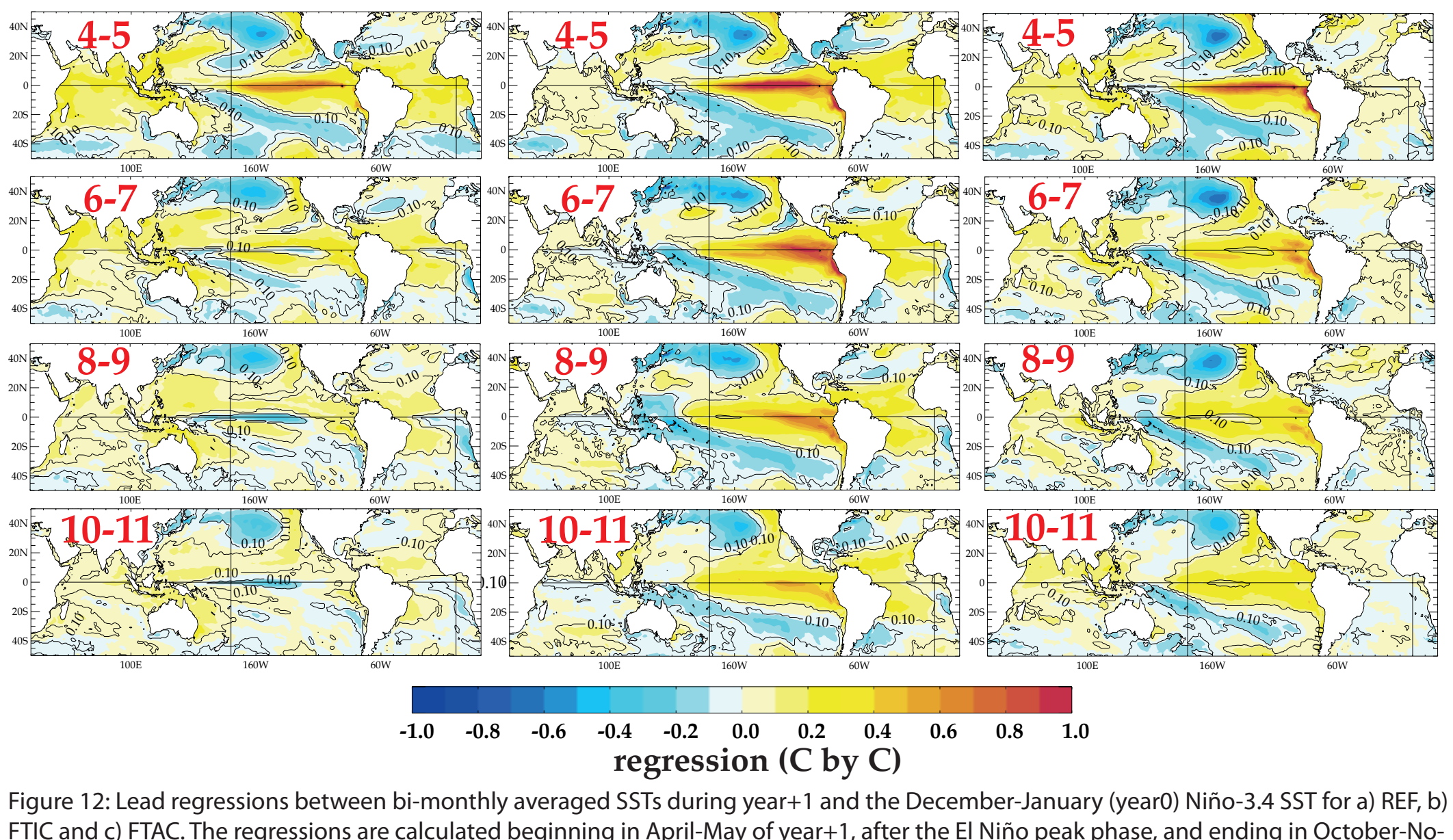

Figure 12: Lead regressions between bi-monthly averaged SSTs during year+1 and the December-January (year0) Niño-3.4 SST for a) REF, b) FTIC and c) FTAC. The regressions are calculated beginning in April-May of year+1, after the El Niño peak phase, and ending in October-November of year +1 . Regressions that are above the $90 \%$ significance confidence level according to a phase-scramble bootstrap test (Ebisuzaki 1997) are underlined. 
Table 1

\begin{tabular}{|c|c|c|c|c|c|}
\hline Name & REF & FTIC & FTIC-obs & FTAC & FTAC-obs \\
\hline $\begin{array}{c}\text { Correction } \\
\text { area }\end{array}$ & None & $\begin{array}{c}\text { Indian Ocean } \\
30^{\circ} \mathrm{E}-120^{\circ} \mathrm{E} \\
25^{\circ} \mathrm{S}-30^{\circ} \mathrm{N}\end{array}$ & $\begin{array}{c}\text { Indian Ocean } \\
30^{\circ} \mathrm{E}-120^{\circ} \mathrm{E} \\
25^{\circ} \mathrm{S}-30^{\circ} \mathrm{N}\end{array}$ & $\begin{array}{c}\text { Atlantic Ocean } \\
100^{\circ} \mathrm{W}-20^{\circ} \mathrm{E} \\
25^{\circ} \mathrm{S}-25^{\circ} \mathrm{N}\end{array}$ & $\begin{array}{c}\text { Atlantic Ocean } \\
100^{\circ} \mathrm{W}-20^{\circ} \mathrm{E} \\
25^{\circ} \mathrm{S}-25^{\circ} \mathrm{N}\end{array}$ \\
\hline $\begin{array}{c}\text { Smoothing } \\
\text { area }\end{array}$ & None & $30^{\circ} \mathrm{S}-25^{\circ} \mathrm{S}$ & $30^{\circ} \mathrm{S}-25^{\circ} \mathrm{S}$ & $\begin{array}{c}30^{\circ} \mathrm{S}-25^{\circ} \mathrm{S} \\
25^{\circ} \mathrm{N}-30^{\circ} \mathrm{N}\end{array}$ & $\begin{array}{c}30^{\circ} \mathrm{S}-25^{\circ} \mathrm{S} \\
25^{\circ} \mathrm{N}-30^{\circ} \mathrm{N}\end{array}$ \\
\hline $\begin{array}{c}\text { SST data } \\
\begin{array}{c}\text { Time } \\
\text { duration } \\
\text { (Year) }\end{array}\end{array}$ & None & $\mathrm{REF}$ & $\mathrm{AVHRR}$ & $\mathrm{REF}$ & $\mathrm{AVHRR}$ \\
\hline
\end{tabular}

Table 1: Summary of the numerical experiments with their main characteristics, including length, nudging domain and SST climatology used for the nudging in the Indian or Atlantic oceans decoupled experiments. 


\section{Table 2}

\section{$\underline{\text { SST standard-deviations }}$}

\begin{tabular}{|c|c|c|c|c|}
\hline Indices & $\begin{array}{c}\text { Niño-3.4 } \\
\text { DJF }\end{array}$ & $\begin{array}{c}\text { ATL3 } \\
\text { JJAS }\end{array}$ & $\begin{array}{c}\text { IOB } \\
\text { AM }\end{array}$ & $\begin{array}{c}\text { IOD } \\
\text { SON }\end{array}$ \\
\hline observations & 1.11 & 0.45 & 0.29 & 0.35 \\
\hline REF & $\mathbf{0 . 8 9}$ & $\mathbf{0 . 3 0}$ & 0.24 & $\mathbf{0 . 5 5}$ \\
\hline
\end{tabular}

Table 2: Standard-deviations (in $\left.{ }^{\circ} \mathrm{C}\right)$ of Niño-3.4 $\left(5^{\circ} \mathrm{S}-5^{\circ} \mathrm{N}, 170-120^{\circ} \mathrm{W}\right)$, ATL3 $\left(5^{\circ} \mathrm{S}-5^{\circ} \mathrm{N}\right.$, $\left.340-360^{\circ} \mathrm{E}\right), \mathrm{IOB}\left(20^{\circ} \mathrm{S}-20^{\circ} \mathrm{N}, 40-110^{\circ} \mathrm{E}\right)$, and IOD SST indices in observations and REF. The IOD index is computed as the differences between the SST anomalies in a western $\left(10^{\circ} \mathrm{S}-10^{\circ} \mathrm{N}, 60-80^{\circ} \mathrm{E}\right)$ and eastern $\left(0-10^{\circ} \mathrm{S}, 90-110^{\circ} \mathrm{E}\right)$ box in the tropical Indian Ocean. The different indices are computed as seasonal averages as defined in the first row of the Table. These seasons correspond to the peak season of the indices in the observations. The statistics for the observations are derived from the HadISST1.1 dataset for the 1979-2012 period. The statistical significance of the differences between the observed and simulated standarddeviations has been assessed with the help of a Fisher test. The simulated standard-deviations significant at the $95 \%$ confidence level are in bold. 
Table 3

$\underline{\text { SST - USTR (zonal wind stress) MCAs }}$

\begin{tabular}{|c|c|c|c|c|c|}
\hline MCA1 & SCF $(\%)$ & NC $(\%)$ & r & SSTvar (\%) & USTRvar(\%) \\
\hline REF & 63 & 10 & 0.74 & 30.2 & 6.1 \\
\hline FTIC & 74 & 12.7 & 0.76 & 39.4 & 7.1 \\
\hline FTIC-obs & 80 & 16.2 & 0.82 & 45.6 & 8.5 \\
\hline FTAC & 74 & 12.3 & 0.78 & 34.7 & 7 \\
\hline FTAC-obs & 72 & 11.8 & 0.79 & 37.2 & 6.8 \\
\hline
\end{tabular}

Table 3 Summary statistics for the SST-USTR MCA leading modes estimated from the REF, FTIC, FTIC-obs, FTAC and FTAC-obs experiments, including the SCFs and NCs for the leading modes in the various MCA expansions and the correlation $(r)$ between the EC time series of the left and right fields. SCF stands for Square Covariance Fraction and NC for Normalized root-mean-square Covariance, as given in the text. As discussed by Zhang et al. (1998), the NC and $r$ coefficients are particularly useful in comparing the strength of the coupling between the left and right fields in modes obtained from different MCAs. SSTvar and USTRvar are, respectively, SST and USTR variances accounted for by the leading mode of each MCA analysis (e.g. this is the variance of the field explained by the related Expansion Coefficient time series by linear regression). 
Table 4

USTR - 20d (depth of $20^{\circ} \mathrm{C}$ isotherm) MCAs

\begin{tabular}{|c|c|c|c|c|c|}
\hline MCA1 & SCF $(\%)$ & NC $(\%)$ & r & USTRvar $(\%)$ & 20dvar(\%) \\
\hline REF & 61 & 7.8 & 0.73 & 6.4 & 17.5 \\
\hline FTIC & 73 & 11.1 & 0.73 & 8.4 & 27.4 \\
\hline FTIC-obs & 68 & 13.2 & 0.81 & 9.3 & 28.3 \\
\hline FTAC & 75 & 10.2 & 0.76 & 7.2 & 24.9 \\
\hline FTAC-obs & 69 & 9.5 & 0.75 & 6.1 & 27.8 \\
\hline
\end{tabular}

Table 4: Same as Table 2, but for the USTR-20d MCA leading modes from the REF, FTIC, FTIC-obs, FTAC and FTAC-obs experiments. 